\title{
Atomic Scale Models of Ion Implantation and Dopant Diffusion in Silicon
}

\author{
Silva K. Theiss \\ M.J. Caturla \\ M.D. Johnson \\ J. Zhu \\ T. I. enosky \\ B. Sadigh \\ T. Diaz de la Rubia
}

March 1, 1999

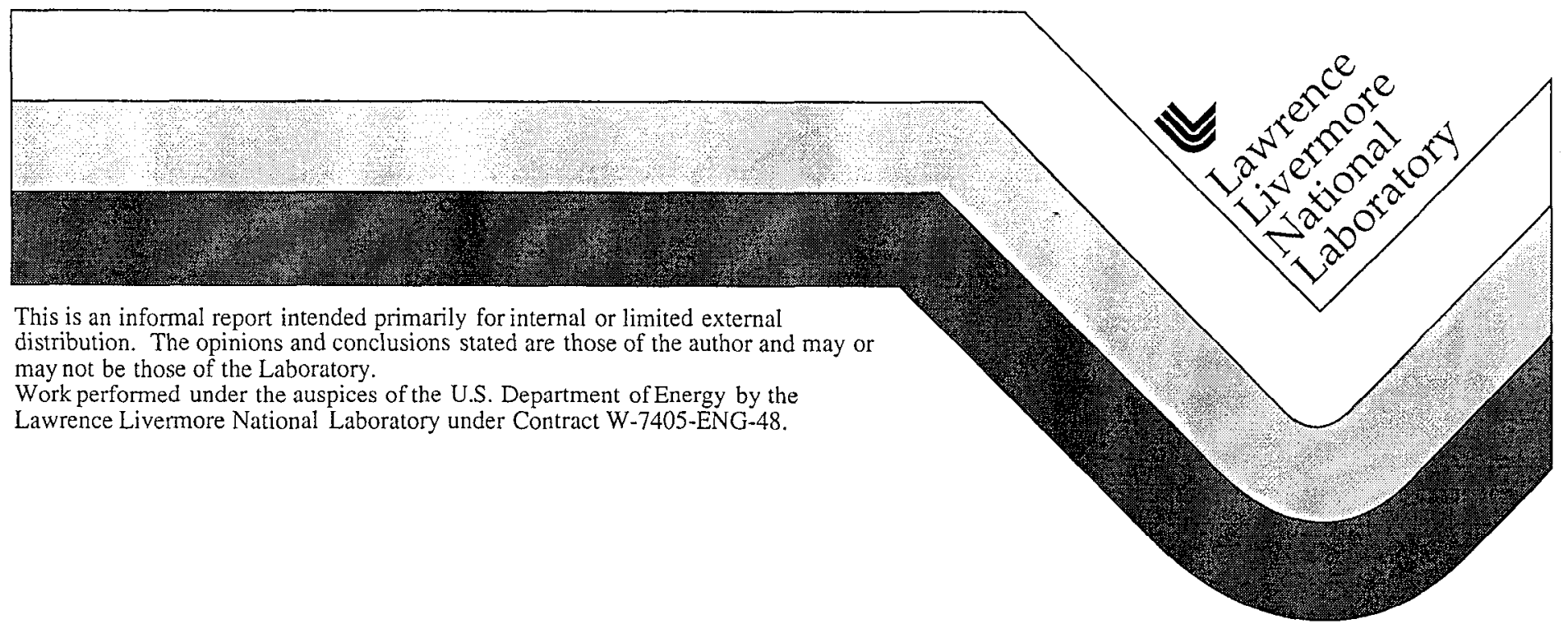




\section{DISCLAIMER}

This document was prepared as an account of work sponsored by an agency of the United States Government. Neither the United States Government nor the University of California nor any of their employees, makes any warranty, express or implied, or assumes any legal liability or responsibility for the accuracy, completeness, or usefulness of any information, apparatus, product, or process disclosed, or represents that its use would not infringe privately owned rights. Reference hercin to any specific commercial product, process, or service by trade name, trademark, manufacturer, or otherwise, does not necessarily constitute or imply its endorsement, recommendation, or favoring by the United States Government or the University of California. The views and opinions of authors expressed herein do not necessarily state or reflect those of the United States Government or the University of California, and shall not be used for advertising or product endorsement purposes.

This report has been reproduced directly from the best available copy.

Available to DOE and DOE contractors from the Office of Scientific and Technical Information

P.O. Box 62, Oak Ridge, TN 37831

Prices available from (423) 576-8401

Available to the public from the National Technical Information Service

U.S. Department of Commerce

5285 Port Royal Rd.

Springfield, VA 22161 


\author{
Atomic Scale Models of Ion Implantation and Dopant Diffusion in Silicon \\ Silva K. Theiss, M.J. Caturla, M.D. Johnson* , J. Zhu ${ }^{\dagger}$, T. Lenosky, B. Sadigh, and \\ T. Diaz de la Rubia \\ University of California, Lawrence Livermore National Laboratory, Livermore, CA 94550 , \\ USA
}

\begin{abstract}
We review our recent work on an atomistic approach to the development of predictive process simulation tools. First principles methods, molecular dynamics simulations, and experimental results are used to construct a database of defect and dopant energetics in Si. This is used as input for kinctic Monte Carlo simulations. C and B trapping of the Si sclfinterstitial is shown to help explain the enormous disparity in its measured diffusivity. Excellent agreement is found between experiments and simulations of transient enhanced diffusion following 20-80 keV B implants into $\mathrm{Si}$, and with those of $50 \mathrm{keV}$ Si implants into complex B-doped structures. Our simulations predict novel behavior of the time evolution of the electrically active $B$ fraction during annealing.
\end{abstract}

\title{
INTRODUCTION
}

To reduce development time and costs, the semiconductor industry makes extensive use of technology computer aided design (TCAD) models aimed at predicting and optimizing the outcome of both front- and back-end-of-line manufacturing processes. Thus, continuum-level phenomenological models of dopant implantation and defect annealing, and of etching and film deposition have been developed. However, the Semiconductor Industry Association projects continued device scaling over the next few years to gate lengths less than $100 \mathrm{~nm} .^{.}$At this scale, atomic-level control of the manufacturing process becomes critical to continued success. Moreover, new materials and processes will probably be required for source/drain engineering, gate electrodes, insulators, contacts, and interconnects. Clearly, a solid fundamental understanding of materials properties and behavior during processing and operation will be essential to success.

The prospect of developing physically-based predictive process simulation tools for semiconductor manufacturing has been a beckoning, yet elusive goal. However, progress in the development of more accurate interatomic potential descriptions of materials, coupled with vast improvements in computational power and speed, have made this goal an attainable reality. Over the last few years, several research groups worldwide in academia, industry, and the National Laboratories have confronted this challenge. As a result, a 
flurry of activity aimed at developing increasingly sophisticated modeling and simulation tools, based on the connection of experimental data and first principles calculations to kinetic models of material evolution, has taken place. In this paper we review results of recent efforts at Lawrence Livermore National Laboratory to develop a first-principlesbased atomistic process simulation tool for modeling ion implantation and rapid thermal annealing (RTA) in Si.

Ion implantation is currently the most widely used method for semiconductor doping. It requires a subsequent thermal treatment of the material in order to eliminate the induced crystal damage and to electrically activate the dopant atoms. During this thermal treatment, dopants can diffuse. While the implantation-induced excess defects are present, the dopant diffusivity can be orders of magnitude larger than it is at equilibrium defect concentrations. This phenomenon is known as transient enhanced diffusion (TED) $.^{2},{ }^{3},{ }^{4},{ }^{5}$ So far, TED has not been a major problem in the development of semiconductor devices. However, as transistors evolve from one generation to the next, the gate length is reduced in order to improve performance. Problems arise when the gate size approaches the diffusion length of the dopant by TED. A fundamental understanding of TED, and the development of predictive models for the defect distribution under different annealing and implantation conditions, are necessary for the design of future devices.

During ion implantation and annealing, the energy and dose of the implant, the highest temperature achieved, and the detailed thermal history (e.g., temperature ramp rates) all influence the final dopant profile. Thus it is important to know what combination of these variables leads to the most favorable final dopant profile with a minimum of residual crystal damage. However, experiments to evaluate the influence of each variable for each new generation of technology are expensive and time-consuming. The ultimate goal of our work is to develop a truly predictive model of dopant TED. Given the implant species, cnergy, dose, and dose ratc, the detailed thermal history, and the impurity concentration, the model would produce the correct three-dimensional final dopant profile, as well as the degree of activation of the dopant and the damage remaining in the Si lattice.

Thus far, models based on rate theory have been most commonly used to investigate diffusion of dopants in semiconductors. ${ }^{6}$ These models are based on mean field theory and solve a coupled set of partial differential equations to provide the time evolution of diffusion in the defect and dopant system. However, most of these models have relied on a set of parameters that had to be fitted in order to reproduce particular experimental observations, limiting their predictive capabilities. In addition, the use of reaction-diffusion equations creates difficulties with the proper description of the nucleation and growth of defect and dopant clusters of all possible sizes. This limits the available kinetic paths of the 
system. In order to be fully predictive, more fundamental models are necessary which include the atomic-scale details of the underlying physical phenomena that occur during irradiation and annealing.

The simulation of phenomena such as dopant diffusion requires long time scales, on the order of seconds to hours, and relatively large length scales, on the order of microns. However, during ion implantation a dopant atom deposits its energy in the crystal in just a few picoscconds, and the fundamental diffusive jumps are but a fraction of a $\mathrm{nm}$. Therefore it is necessary to use a model that can link microscopic times and length scales, such as those required for defect production, with those of macroscopic phenomena, such as the dopant profile evolution. We bridge these time scales using a kinetic Monte Carlo (kMC) model, which takes as input a database of diffusion and binding energies obtained from fundamental experimental and theoretical methods, and which can produce as output three dimensional dopant and defect distributions over the course of hours of annealing.

\section{METHOD}

In our approach, fundamental diffusion and reaction barriers are obtained from $a b$ initio planewave pseudopotential calculations or molecular dynamics (MD) simulations with tight binding or empirical interatomic potentials. These numbers are combined with experimental data to extract pre-exponential factors, and hence diffusion and reaction rates. The cascade of vacancies (Vs) and interstitials (Is) created by each energetic ion implanted into a Si crystal is simulated with the extended binary collision approximation model, UT Marlowe. ' Our kMC simulator uses these inputs to produce a three dimensional, atomicscale description of dopant, defect, and impurity diffusion and clustering, on laboratory time and length scales.

In the following sub-sections, we first describe the $\mathrm{kMC}$ simulator in some detail, and then discuss the origin of the input parameters it requires.

\section{Kinetic Monte Carlo Simulation}

The $\mathrm{kMC}$ simulations of damage accumulation and defect and dopant diffusion in $\mathrm{Si}$ described below were performed using the BIGMAC code developed by Johnson, Caturla and Diaz de la Rubia. The use of $\mathrm{kMC}$ to model defect diffusion during irradiation of materials has been rather sparse in the past, but the technique dates back over thirty years and has been discussed extensively by Beeler. ${ }^{8}$ The earliest reference to this method is the work of Besco in 1967. ${ }^{9}$ Doran, $^{10}$ and Doran and Burnett ${ }^{11}$ carried out short term annealing simulations of displacement cascades in fcc and bcc Fe, respectively, using a Beckman 2133 analog computer and a PDP-7 with 8K of memory. More recently, 
Heinisch et al. ${ }^{12}$ used a Monte Carlo code named ALSOME to model the migration, agglomeration and dissociation of the defects produced by $25 \mathrm{keV} \mathrm{Cu}$ self-irradiation at different temperatures. Within our own group, we have used the BIGMAC code to model defect escape from cascades in $\mathrm{Fe}^{13}$ and $\mathrm{Au}^{14}$ and as we shall show below, dopant implantation and diffusion in $\mathrm{Si}^{15,16,17,18}$ The first application of the kMC method to model defect diffusion in Si was reported by Jaraiz et al. ${ }^{19}$ and the method has since been used extensively by that group to model implantation and diffusion of defects and dopants in $\mathrm{Si}^{20}$

BIGMAC is a computationally efficient $\mathrm{kMC}$ program based on that of Heinisch et $a l .{ }^{12}$ As a function of time, it tracks the locations of defects, dopants, impurities, and clusters thereof. These various species are all treated as point particles with basic attributes such as size, diffusivity, and dissociation rates. Additionally, we can include microstructural features such as dislocations, surfaces and grain boundaries, which are treated as sinks of differing strengths. The data required to carry out these simulations are quantities such as the temperature-dependent diffusivities of defects, dopants, and impurities; the binding energies of clusters; the spontaneous recombination volume of vacancies and interstitials; the capture radius of point defects at clusters and extended defects; and the jump distance.

The temperature dependence of the diffusivity can be written as $\mathrm{D}=\mathrm{D}_{0} \exp \left(-\mathrm{E}_{\mathrm{m}} / \mathrm{kT}\right)$,

where $D$ is the diffusivity, $D_{0}$ the pre-exponential factor, $E_{m}$ the migration energy, $T$ the temperature of the crystal, and $\mathrm{k}$ Boltzmann's constant. A similar form applies for dissociation rates from clusters, with $\mathrm{E}_{\mathrm{m}}$ replaced by a dissociation energy that includes the binding energy, $E_{b}$, of a particle to the cluster. Specifically, the effective diffusivity for a free particle leaving a cluster is taken as

$\mathrm{D}=\mathrm{D}_{0} \exp \left[-\left(\mathrm{E}_{\mathrm{b}}+\mathrm{E}_{\mathrm{m}}\right) / \mathrm{kT}\right]$,

because the particle must migrate one jump distance away from the cluster to be free. The BIGMAC program requires input tables of $\mathrm{D}_{0}$ and $\mathrm{E}_{\mathrm{m}}$ for all mobile species, as well as the prefactors and binding energies for all possible clusters. The input tables can become rather large, but the program is very flexible, as only the input tables need to be changed to study another set of conditions or even another material system.

During the simulation various kinetic processes are allowed to take place. The possible events are: (i) the dissociation of a particle from a cluster; (ii) the diffusive jump of a particle; and (iii) the introduction of a new cascade, that is, a new energetic dopant and all its associated Vs and Is. The dissociation and migration rates are given by $R=\left(6 D / \delta^{2}\right)$, 
where $\delta$ is the jump distance set by the lattice, and the appropriate value of $\mathrm{D}$ from equations (1) and (2) above are used. The rate of cascade introduction is the dose rate of the simulated implantation. At each time step, we randomly choose among all possible events, ensuring that events occur at the proper rate by assigning each event a probability proportional to its rate. Following each chosen event, we perform all events that occur spontaneously as a result of that event. For example, an I which jumps within the capture radius of an I cluster will then spontaneously join the cluster. The simulation time is then incremented by the inverse of the sum of the rates for all possible events in the simulation box:

$\Delta \mathrm{t}=\chi \cdot\left(\sum_{i} \mathrm{~N}_{i} \cdot \mathrm{R}_{i}\right)^{-1}$

where the sum is over all possible events which can occur in the simulation box, $\mathrm{N}_{i}$ is the number of particles in the box that can take part in event $i$, and $\mathrm{R}_{i}$ is the rate of event $i$ from equation (3). $\chi$ is a random deviate that gives a Poisson distribution in the time steps, so that they take a randomly distributed amount of time, but the average time for any event is given by the inverse of its rate. The time step increases when the number of possible events decreases or the event rate is slower. Because a kinetic process occurs for every Monte Carlo step during a kMC run, time scales of hours can be reached with these simulations. Clearly, care must be taken to completely enumerate the relevant particles and events. A schematic diagram of the operation of the kMC simulation is shown in Fig. 1.

\section{Input to $\mathrm{kMC}$}

The kMC simulations will not properly reflect reality unless the input files accurately represent the important physical phenomena underlying the effect of interest. The values used for the migration and clustering of $\mathrm{B}, \mathrm{C}$, and $\mathrm{Si}$ Is and Vs are discussed in the next subsection. Then the origin of the input files necessary to match ion implantation experiments are presented.

\section{Parameter Files}

The basic input data necessary for the simulation of dopant diffusion are migration energies and binding energies of Vs, Is, dopants, and impurities. Additionally, we must know the pre-exponential factors in order to determine the migration and dissociation rates. The required values can be obtained from different sources, both theoretical and, in some cases, experimental. The origin of the values used as input to our $\mathrm{kMC}$ simulation are shown in Table 1 and discusscd in detail below. 
Recent computer simulations have provided a better understanding of defect production, diffusion, and clustering in Si. V and I formation and migration energies have been obtained using $a b$ initio simulations, ${ }^{21,22,23}$ tight binding molecular dynamics ${ }^{24}$ and empirical-potential molecular dynamics. ${ }^{25}$ These quantities have not been independently determined experimentally, and controversy exists regarding their values. The cause of the wide range of experimentally determined values for the diffusivity of the Si self-interstitial will be discussed further below. Prefactors for $\mathrm{V}$ and I diffusion have been obtained from MD simulations. However, in recent experiments, Coffa and Libertino were able to separately determine the $\mathrm{V}$ and I components of Si diffusivity at room temperature. ${ }^{26}$ Based on these data and calculated migration energies, we have extracted prefactors for $\mathrm{V}$ and I migration.

When the implantation-induced defect supersaturation is large enough, Vs and Is form clusters. Values for the binding energies of small $\mathrm{V}$ and I clusters have been determined by tight binding and empirical potential MD simulations. ${ }^{25,27,28,29}$ The binding energy for an infinitely large vacancy cluster was taken as the (calculated) formation energy of a vacancy, and the binding energy of an infinitely large interstitial cluster was determined from the experimentally measured binding energy for large $\{311\}$ defects, which are extended clusters of $\mathrm{Si}$ interstitials. ${ }^{30}$ Clusters of intermediate sizes were assumed to lie on a smooth interpolation between the small cluster energies and the infinite cluster energies. The prefactors for cluster dissolution were taken to be the same as those for the migration of the free species.

The energetics of dopants and impurities (e.g., C) have also been studied using $a b$ initio calculations. These can provide accurate information about the migration paths for dopants such as B and $\mathrm{P},{ }^{21,23}$ and about the binding energies of Vs and Is with dopant or impurity atoms. ${ }^{31,32,33} \mathrm{~B}$ is a pure interstitial-type diffuser. ${ }^{34}$ It diffuses via a "kick-out" mechanism, with the aid of Si interstitials. ${ }^{21,35,36}$ An I binds with a substitutional B, forming the immobile cluster BI. Then there is some probability for the Si atom to "kick" the $\mathrm{B}$ atom off of its lattice site, creating interstitial B, Bi. Although it is in a higher energy state than the immobile BI, Bi can diffuse very rapidly. There is an energy barrier for "kick-in", when it returns to its substitutional state by displacing a $\mathrm{Si}$ atom into an interstitial site. A Bi may bind to B to form B2I, and a mobile I to may join a BI pair to form BI2. These clusters in turn can grow with the addition of more Is and Bis. Thus we need the binding energies for clusters of B atoms and Si interstitials. Values for such B clusters from $a b$ initio calculations are shown in Fig. 2. These are complex calculations, and the values in the table are continually being updated as first principles methods and algorithms advance. 
Prefactors for B migration were obtained from a combination of experimental data and $\mathrm{kMC}$ simulations. Because of the kick-out mechanism, there are five events that occur during the migration of a $\mathrm{B}$ atom from one substitutional site to another:

1. $\mathrm{B}+\mathrm{I} \rightarrow \mathrm{BI}$

2. $\mathrm{BI} \rightarrow \mathrm{Bi} \quad$ ("kick out")

3. Bi migrates

4. $\mathrm{Bi} \rightarrow \mathrm{BI}$ ("kick in")

5. $\mathrm{BI} \rightarrow \mathrm{B}+\mathrm{I}$

Event 1 is assumed to occur spontaneously any time an I approaches a within a capture radius $(0.235 \mathrm{~nm})$ of $\mathrm{B}$, and thus we are not concerned with its prefactor. The experimentally determined prefactor for equilibrium B diffusion is a complicated, temperature-dependent function of the prefactors for the remaining four reactions. Therefore we assume a prefactor based on the Debye frequency in $\mathrm{Si}$ for all four reactions $\left(\mathrm{D}_{0}=v_{\mathrm{D}} \bullet \delta^{2} / 6=1 \times 10^{-3} \mathrm{~cm}^{2} / \mathrm{s}\right)$, and monitor a $\mathrm{kMC}$ cell with periodic boundary conditions in which we originally have one substitutional B and one I. Based on the number of hops taken by the $\mathrm{B}$ atom (as $\mathrm{Bi}$ ) as a function of temperature, and adjusting for box size effects and interstitial concentration, we obtain a value for the equilibrium $\mathrm{B}$ diffusivity. The prefactor for $\mathrm{Bi}$ migration is adjusted until the temperature dependent diffusivity in the simulation matched that determined experimentally. ${ }^{37}$

The prefactors for the dissolution of B-I clusters are assumed to be determined by the prefactor for migration of the departing species. That is, the prefactor for the reaction $\mathrm{B} 2 \mathrm{I} \rightarrow \mathrm{BI}+\mathrm{I}$ is taken to be that for I migration, while that for $\mathrm{B} 2 \mathrm{I} \rightarrow \mathrm{B}+\mathrm{Bi}$ is taken to be that for Bi migration. These values are not independently determined, and may be adjusted (within limits) to change the time for dissolution of the B clusters.

Energetics for the trapping of Is by $\mathrm{C}$ have also been determined by ab initio calculations. This interaction can be summed up as follows:

$$
\begin{aligned}
& \mathrm{C}+\mathrm{I} \leftrightarrow \mathrm{CI} \\
& \mathrm{CI}+\mathrm{C} \leftrightarrow \mathrm{CIC} .
\end{aligned}
$$

Thus there are two types of traps for the Si interstitial: a mobile trap with a single $\mathrm{C}, \mathrm{CI}$, formed by the Watkins replacement mechanism, ${ }^{38,39}$ and an immobile complex, CIC, formed when a mobile $\mathrm{CI}$ interacts with a substitutional $\mathrm{C}$ atom. ${ }^{40,41}$ It is possible for the CI pair to dissolve, releasing a free self-interstitial I. This interaction leads to an effective 
diffusivity for the self interstitial which is higher than one would obtain for a simple fixed trap but far less than the bare I diffusivity -- even for modest concentrations of $\mathrm{C}$. The prefactor for $\mathrm{CI}$ migration was obtained by a fitting to experimental measurements of $\mathrm{C}$ diffusivity, ${ }^{42}$ similarly to the technique described above for obtaining the factor for $\mathrm{Bi}$ migration.

These reaction rates are fundamental parameters for any Monte Carlo simulation of defect and dopant diffusion in Si. The initial conditions or boundary conditions will change depending on the type of experiment to be simulated: ion implantation, oxidation enhanced diffusion (OED), etc. In particular, for ion implantation it is necessary to obtain the initial configuration of the Vs and Is created in the Si lattice by the energetic ions, as discussed next.

\section{Ion Implantation -- Cascades}

The distribution of the dopant atoms after implantation can be accurately modeled by binary collision codes, such as UT Marlowe. ${ }^{7}$ UT Marlowe was developed by A.F. Tasch and co-workers at the University of Texas and is based on the original code of M.T. Robinson at Oak Ridge National Laboratory. ${ }^{43}$ This code has been discussed extensively elsewhere and will therefore not be described in detail here. In essence, it allows simulation of different implanted species, energies, angles and doses in Si. In the binary collision approximation, two atoms interact according to a simple repulsive interatomic potential, and it is assumed that collisions occur between a moving and a stationary atom only. Many-body effects that arise in dense collision cascades are ignored. The implanted ion undergoes a series of binary collisions with the lattice atoms. The recoiling lattice atoms collide with other lattice atoms, and so on. Thus the simulation also provides information about the cascade of defects produced by each implanted ion; that is, the location of all the Vs and Is produced during the irradiation. The defect distribution obtained from this model is valid for irradiation with light ions, when the damage is primarily in the form of V-I pairs (Frenkel pairs) and no direct amorphization is produced by the implanted ions.

\section{RESULTS}

\section{Diffusivity of the $\mathrm{Si}$ interstitial}

\section{C trapping}

One of the most important parameters in a microscopic model for dopant TED in Si is the diffusivity of the Si self-interstitial. Unfortunately, values for the interstitial diffusivity reported in the literature vary over at least 5 orders of magnitude at typical dopant activation 
annealing temperatures $\left(800-1000^{\circ} \mathrm{C}\right) .{ }^{44,45,46}$ It has been suggested that trapping of selfinterstitials by different concentrations of $\mathrm{C}$ impurities may play a role in the differences reported.

In order to examine the effect of $\mathrm{C}$ on self interstitial diffusion, we performed $\mathrm{kMC}$ simulations in which we fixed the I population at the surface, $\mathrm{C}(\mathrm{I}, 0)$, and monitored the evolution of the I depth profile with time. For pure I diffusion the concentration profile should follow

$\mathrm{C}(\mathrm{I}, \mathrm{x})=\mathrm{C}(\mathrm{I}, 0) \operatorname{erfc}\left\{\mathrm{x} / \mathrm{sqrt}\left(4 \mathrm{D}_{\mathrm{I}} \mathrm{t}\right)\right\}$, where $D_{I}$ is the effective I diffusivity and $x$ is depth. In the simulations, the I surface concentration was maintained at $1 \times 10^{12} \mathrm{~cm}^{-3}$ and the $\mathrm{C}$ concentration was varied from 0 to $1 \times 10^{18} \mathrm{~cm}^{-3}$. In the presence of $\mathrm{C}$, the I profile is not expected to be a pure complementary error function; however, we find that the data can be closely fit with this function, and it allows us to calculate a diffusivity. By performing simulations at temperatures betwecn 700 and $1000^{\circ} \mathrm{C}$, we create Arrhenius plots of the effective diffusivity of the Si selfinterstitial for different $\mathrm{C}$ concentrations, as shown in Fig. 3. Notice that the $\mathrm{C}$ not only changes the prefactor for the diffusivity, but also dramatically increases the effective I migration energy, from $0.9 \mathrm{eV}$ for no $\mathrm{C}$ to $1.98 \mathrm{eV}$ for $1 \times 10^{18} \mathrm{C} / \mathrm{cm}^{3}$.

These results suggest an explanation for the vast spread in the experimentally determined I diffusivity. Fig. 4 shows a comparison between our results and two general classes of experiments. One class involves monitoring the diffusion of metal tracers. These follow the same general trend of shallower slopes at higher values of diffusivity and steeper slopes for lower values of the diffusivity ${ }^{45,47,48,49,50}$ as our simulations do, with a few notable exceptions. ${ }^{51,52,53,54}$ (See Ref. 45 for a detailed comparison of the experiments). In the second class of experiments, the spreading of doped marker layers during OED is monitored. ${ }^{44,46,55,56,57}$ In this case, a much lower diffusivity has been measured and activation energies for migration were determined to be in the range of 3.1 $\mathrm{eV}$. These results cannot be explained only by $\mathrm{C}$ trapping of Is. In order to understand these data, we must also include the effect of B as an I trap, as discussed next.

\section{B trapping}

In order to understand and help interpret the results of the B-spike OFD experiments, we have used our kMC code to simulate the spreading of B spikes during OED and under the same conditions as the experiments of Gossmann et al. ${ }^{55}$ The OED simulations were carried out as described above, but in this case the starting bulk consisted of a set of B 
delta-doped spikes within a Si matrix, see Fig. 5. A background concentration of $5 \times 10^{17} \mathrm{~cm}^{-3} \mathrm{C}$ was included, which is about the level to be expected in epitaxially grown Si. The surface concentration of Si self-interstitials was maintained at $2 \times 10^{10} \mathrm{~cm}^{-3}$ and the annealing temperature was $810^{\circ} \mathrm{C}$. Simulations were carried out for samples with six spikes with a maximum $B$ concentration of $1 \times 10^{18}$ and $1 \times 10^{19} \mathrm{~cm}^{-3}$. For the case of low B concentration, the agreement between the experiments and the simulations is excellent. However, this is not the case for the simulations on the high $\mathrm{B}$ concentration spikes. We will return to the disparity in the high concentration case at the end of the section. First, we use the low concentration simulations to extract the effective diffusivity of the Si self interstitial two different ways.

The first method to determine the diffusivity of the Si self interstitial is to measure the width of the as-deposited and annealed spikes to calculated the $\mathrm{B}$ diffusivities. The diffusivity of the Si self-interstitial is extracted from the B diffusivity profiles by fitting the spreading of the peaks with a Gaussian and assuming the B diffusivity is proportional to the self-interstitial concentration. This is the method that would be used in an experiment. The depth dependent $\mathrm{B}$ diffusivity extracted from these simulations is shown in Fig. 6(a). This method gives similar results to Gossmann's analysis for low B concentrations where a simple diffusion model with traps is used to fit the diffusivity. B-I clusters are a small fraction of the total $\mathrm{B}$, so the spreading of the peaks is expected to give a good measure of the effective diffusivity. Fig. 6 shows the results of such a procedure on the simulated profiles. The agreement between the simulations and the experimental data for the low $\mathrm{B}$ concentration case is excellent.

The second method to determine the diffusivity of the $\mathrm{Si}$ interstitial was to examine directly the simulated interstitial concentration profile in the low concentration spike spreading experiment. We find that the spike spreading method gives a diffusivity of $2.2 \times 10^{-12} \mathrm{~cm}^{2} / \mathrm{s}$ while a fit to the interstitial concentration profile yields an effective diffusivity of $3.6 \times 10^{-12} \mathrm{~cm}^{2} / \mathrm{s}$. The difference is within the accuracy of the simulation, and the result supports the idea that B spike width spreading measures the interstitial profile. However, both of these methods give a Si self-interstitial diffusivity which is orders of magnitude smaller than the diffusivity we measure for a system with no $\mathrm{B}$, only $\mathrm{C}\left(\sim 1 \mathrm{x} 10^{-8}\right.$ $\mathrm{cm}^{2} / \mathrm{s}$, see Fig. 3). Yet B comprises only about $25 \%$ of the total number of traps within the delta-doped region. The effect is due to the fact that the first order $\mathrm{C}$ trap, CI, is still mobile, with a diffusivity of about $2 \times 10^{-9} \mathrm{~cm}^{2} / \mathrm{s}$ at $810^{\circ} \mathrm{C}$, while the $\mathrm{BI}$ complex is immobile. Thus a combination of $\mathrm{C}$ and $\mathrm{B}$ trapping of Si interstitials can reconcile the large 
differences in diffusivity obtained from the different experiments designed to measure the diffusivity of the Si self-interstitial.

Next we consider the high concentration B spikes. For this case, the spreading of the $\mathrm{B}$ markers is much less in the simulations than is observed in the experiments. The simulations show a lower effective diffusivity for the high concentration spikes due to the trapping of self-interstitials in B-I complexes and clusters. The dashed line in Fig. 5(b) shows the population of interstitials which are in immobile species for the high $\mathrm{B}$ concentration spikes. For comparison, the low concentration spikes had a peak cluster concentration of about $1 \times 10^{11} \mathrm{~cm}^{-3}$, almost four orders of magnitude less than the high concentration spikes. The concentration profile of freely diffusing self-interstitials is shown in Fig. 6(b). Clearly the high concentration B spikes strongly perturb the I population, but no reduction in B diffusivity was observed in the experiments. We believe that the discrepancy is a result of the fact that at high $\mathrm{B}$ concentrations the diffusivity of $\mathrm{B}$ increases $^{58,59,60}$ due to the increased concentration of charged Is and Bis, which have a different migration and formation energy than their neutral counterparts. This effect is not yet included in our model. Thus the higher diffusivity of $\mathrm{B}$ in extrinsic material could offset the reduction in diffusivity due to increased trapping.

\section{$40 \mathrm{keV} B$ implantation}

We have done a series of simulations of the TED of implanted B as a function of temperature and time, and as a function of the energy of the implanted B. A constant dose of $2 \times 10^{14} \mathrm{~cm}^{-2}$ was used in all cases.

\section{Temperature Dependence}

Fig. 7 shows the B concentration depth profile for a $40 \mathrm{keV} \mathrm{B}$ implant at $2 \times 10^{14} \mathrm{~cm}^{-2}$ after an anneal at $700^{\circ} \mathrm{C}$ for $240 \mathrm{~min}$, at $800^{\circ} \mathrm{C}$ for $60 \mathrm{~min}$., and at $900^{\circ} \mathrm{C}$ for $5 \mathrm{~min}$. The kMC results for the total B concentrations profiles (circles) are in good agreement with the experimental measurements for these conditions.

In Fig. 8 we show the concentration of the most important B-I clusters as a function of time during the $800^{\circ} \mathrm{C}$ anneal. The percentage of electrically active (substitutional) $\mathrm{B}$ is also shown, on the right axis. After implantation, most of the B-I clusters are in the form $\mathrm{BI}$ and BI2. Only $56 \%$ of the B is active immediately after the room temperature implant. At this time, all vacancies are in clusters and most of the interstitials are isolated defects. During the early stages of the high temperature anneal, interstitials agglomerate to form 
clusters and vacancy clusters grow and then dissolve. The average cluster size of Vs and Is as a function of annealing time is shown on the left axis in Fig. 9. The high concentration of vacancies makes recombination with B-I complexes very likely, and thus a reduction in the concentration of these clusters is observed during the initial annealing stages. As the Si interstitials in the small B-I complexes are consumed, the concentration of substitutional B increases, with a total activation of $98 \%$ at $10^{-2} \mathrm{~s}$ at $800^{\circ} \mathrm{C}$. This large active fraction persists until almost $10 \mathrm{~s}$ annealing time. Note that temperature ramps were not included in this simulation: the temperalure was set to $800^{\circ} \mathrm{C}$ following the room temperalure implantation simulation. The increase in the active fraction of $\mathrm{B}$ would presumably occur before the end of the temperature ramp during rapid thermal processing, but it should still last several seconds into the anneal.

After approximately $10 \mathrm{~s}$ all the vacancies have recombined with interstitials or with the surface, as seen in Fig. 9. After this point in Fig. 8, we can see that stable B3I clusters begin to grow and the electrically active fraction of $\mathrm{B}$ decreases. The average size of the interstitial clusters also increases due to Ostwald ripening (Fig. 9): the larger clusters are better sinks than the small ones, so the large clusters grow while the small clusters dissolve. The best sink in the system is, of course, the surface, so when enough clusters have dissolved that the spacing between clusters becomes greater than the cluster-surface distance, all the clusters will tend to shrink.

The magnitude of B TED is also shown as a function of time in Fig. 9. Interestingly, of the $48 \mathrm{~nm}$ of total $\mathrm{B}$ diffusion length, $8 \mathrm{~nm}$ occurs during vacancy cluster growth and dissolution, $36 \mathrm{~nm}$ during interstitial cluster ripening, and only $4 \mathrm{~nm}$ during the final I cluster (i.e., $\{311\}$ defect) dissolution.

From the simulations described above we have extracted the B diffusivity at the end of the transient as a function of annealing temperature. This has been obtained by counting the total number of hops made by all the B interstitials in the simulation, until the time when no more Si self-interstitials are left in the bulk and all the B atoms are either in substitutional sites or in stable clusters such as B3I. In Fig. 10 we present the results for the B diffusivity as a function of temperature (circles, left axis). The temperature-dependent diffusivity extracted from this plot is $\mathrm{D}_{\mathrm{B}}=2.2 \times 10^{-2} \exp (-2.7 \mathrm{eV} / \mathrm{kT}) \mathrm{cm}^{2} / \mathrm{s}$, in good agreement with the experimental results of Solmi and Baruffaldi, who found $\mathrm{D}_{\mathrm{B}}=2.2 \times 10^{-2} \exp (-2.5 \mathrm{eV} / \mathrm{kT}) \mathrm{cm}^{2} / \mathrm{s}^{61}$ Also in Fig. 10 we show the total diffusion length after the transient as a function of temperature (squares, right axis). As reported in some experimental observations, ${ }^{62}$ the total diffusion length at the end of the transient is 
lower for higher annealing temperatures. Thus the diffusion profiles and the diffusivity as a function of temperature are accurately predicted by this model.

\section{Energy Dependence}

The energy dependence of TED has been studied using kMC simulations and compared with experimental results. In Fig. 11 we present the results for B concentration depth profiles at the same dose reported above, $2 \times 10^{14}$ ions $/ \mathrm{cm}^{2}$, and two additional energies, (a) $20 \mathrm{keV}$ and (b) $80 \mathrm{keV}$. Experimental profiles following a $800^{\circ} \mathrm{C}, 60$ minute anneal are shown by solid lines. The total B profile predicted by kMC is shown by circles, and the total $\mathrm{B}$ in clusters is shown by $\times \mathrm{s}$. Again, there is good agreement between the experiments and the simulation.

As in the case of the varying temperatures above, we have calculated the B diffusivity as a function of energy. In Fig. 12 we show the B diffusivity (left axis, circles) for three different energies and the same dose and annealing conditions. As observed experimentally ${ }^{63}$ there is a minimal dependence of TED on energy at these energy levels. The slight decrease in diffusivity with decreasing implant energy reflects the proximity of the surface to the peak of the implant damage: the closer the $\mathrm{Si}$ interstitials are to this large sink, the less B diffusion they can induce before being absorbed at the surface. The areal density of Si interstitials which have recombined at the surface at the end of the $60 \mathrm{~min}$., $800^{\circ} \mathrm{C}$ anneal is shown on the right axis in Fig. 12. As expected, more interstitials have been absorbed at the surface for the lower energy implants.

\section{Diffusion of $B$ Marker Layers}

B TED was also studied in B spike structures grown by chemical vapor deposition (CVD) with implant damage created by subsequent $\mathrm{Si}$ ion implantation. The test structures consisted of several B concentration spikes of amplitude $1 \times 10^{19} \mathrm{~cm}^{-3}$ created during the deposition of a $1 \mu \mathrm{m}$ thick epitaxial Si layer. Implant damage was created by bombarding the structure with $5 \times 10^{13} \mathrm{Si}$ ions $/ \mathrm{cm}^{2}$ at $50 \mathrm{keV}$. A rapid thermal anneal (RTA) was performed at temperatures between 750 and $1050^{\circ} \mathrm{C}$ for times between 15 and $255 \mathrm{~s}$. Temperature ramp rates for the RTAs were $150^{\circ} \mathrm{C} / \mathrm{s}$ for the $750^{\circ} \mathrm{C}$ anneals and $100^{\circ} \mathrm{C} / \mathrm{s}$ for the others.

We assume a uniform background $\mathrm{C}$ concentration of $1 \times 10^{16} \mathrm{~cm}^{-3}$, which is reasonable for CVD Si. Additionally, we assume that the front surface of the sample is a 
perfect sink for $\mathrm{V}, \mathrm{I}$, and $\mathrm{Bi}$. As discussed above, it is reasonable (within limits) to treat the prefactors for cluster dissolution as fitting parameters. We adjusted the prefactor for the dissolution of the BI pair down by a factor of one-third from the prefactor for I diffusion, and that for the B3I dissolution up by a factor of two from the prefactor for Bi diffusion, in order to improve the match to the experimental data. The same prefactors were used in all the simulations.

Results of the simulations are shown in Fig. 13. The as-grown B profile, taken as input to the simulations, is shown by the dashed line. The experimentally determined total $\dot{B}$ profile after annealing is shown as the solid line in each plot. The simulated total B profile is marked by filled circles, and the concentration of B3I clusters is marked by Xs. Fig. 13(a) and (b) show good agreement between the simulations and experiments for both 15 and $255 \mathrm{~s}$ at $750^{\circ} \mathrm{C}$. Note that the concentration of B3I clusters is the same at $15 \mathrm{~s}$ and at $255 \mathrm{~s}$. In fact, all B3I clusters in the simulation form during the initial temperature ramp. Fig. 13(c) shows excellent agreement between experiment and simulations after $195 \mathrm{~s}$ at $850^{\circ} \mathrm{C}$. The predicted profile of $\mathrm{B} 3 \mathrm{I}$ clusters is the same as in the $750^{\circ} \mathrm{C}$ simulations. Reasonable agreement is also obtained for $150 \mathrm{~s}$ at $950^{\circ} \mathrm{C}$ (not shown), although the simulation predicts too little diffusion in the deepest B peak. Some of the B3I clusters that form during the initial temperature ramp have dissolved after $150 \mathrm{~s}$ at $950^{\circ} \mathrm{C}$. The $1050^{\circ} \mathrm{C}$ simulation grossly underestimates the experimental diffusion, as shown in Fig. 13(d). Experimentally, the deeper two B peaks have completely merged and become a shoulder on the first peak, whereas the model still predicts three distinct peaks. Further, all B and I clusters have dissolved and all defects have been eliminated from the simulation box by $60 \mathrm{~s}$ simulation time. It appears that some additional mechanism which is not accounted for in the model is having a profound effect.

This additional mechanism is not equilibrium $B$ diffusion. The equilibrium diffusion length of $\mathrm{B}$ was calculated to be only $20 \mathrm{~nm}$ after $100 \mathrm{~s}$ at $1050^{\circ} \mathrm{C}$. Additionally, we checked the effect of an equilibrium concentration of $\mathrm{Si}$ interstitials in our $\mathrm{kMC}$ simulation. The equilibrium number of $\mathrm{Si}$ interstitials in a sample the size of our simulation box was calculated to be about 0.1 . We added a $\mathrm{Si}$ interstitial in a random position after the end of the transient, and set both the front and back surfaces reflecting. The interstitial had a minimal effect on the $\mathrm{B}$ profile after $10 \mathrm{~s}$ additional simulation.

The effect may turn out to be due to unexpected OED. Felch and co-workers have shown that adding $300 \mathrm{ppm} \mathrm{O}_{2}$ to the RTA gas can increase the junction depth more than $30 \mathrm{~nm}$ in $10 \mathrm{~s}$ at $1050^{\circ} \mathrm{C}^{64}$ Further, it has been shown that hundreds of $\mathrm{ppm}$ of $\mathrm{O}_{2}$ can 
outgas from the surface of a nominally oxide-free wafer at these temperatures, ${ }^{65}$ which might then cause OED. Further experimental work is required to identify the time scale and source of the observed diffusion.

\section{CONCLUSIONS}

We have described some recent simulations of defect and dopant diffusion using a kinetic Monte Carlo approach. We have shown that the trapping of Si interstitials by both $\mathrm{C}$ and $\mathrm{B}$ can help explain the enormous variation in their measured diffusivity. Excellent agreement was found between experiments and simulations for TED at temperatures between $700^{\circ}$ and $900^{\circ} \mathrm{C}$ following medium energy $\mathrm{B}$ implants $(20-80 \mathrm{keV})$. Our simulations produced novel predictions of the time evolution of the electrically active $\mathrm{B}$ fraction during annealing, which provide an intriguing possibility for experimental verification. Good agreement was also found between experiments and simulations of TED following $50 \mathrm{keV} \mathrm{Si} \mathrm{ion} \mathrm{implantation} \mathrm{into} \mathrm{CVD-grown} \mathrm{B} \mathrm{spike} \mathrm{structures} \mathrm{at}$ temperatures up to $950^{\circ} \mathrm{C}$. For anneals above $950^{\circ} \mathrm{C}$, our simulations do not correctly predict the amount of diffusion. This may be due to unexpected processes, such as OED, occurring in the experiment, or it may be due to a heretofore unexplored limitation of the physics in the model. Additional first principles calculations are under way with the expectation that improving the accuracy of the input parameters for the initial stages of B-I clustering and mobile Bi formation will improve the results of these simulations. Another area requiring further investigation for predicting the properties of future devices is the recombination efficiency of defects and dopants at surfaces, since the interactions of defects with the $\mathrm{Si} / \mathrm{SiO}_{2}$ interface is not fully understood. This is a critical issue when the implantation energies are reduced, so that most of the damage is concentrated near the surface. $\Lambda$ dditionally, Fermi level effects on dopant diffusion will become even more important as peak dopant concentrations approach $10^{20} \mathrm{~cm}^{-3}$ and beyond. We are in the process of including such effects in our model.

\section{ACKNOWLEDGMENTS}

Martin Giles of Intel Corporation and Peter Griffin and Ant Ural of Stanford University respectively provided us with $40 \mathrm{keV} \mathrm{B}$ implant and the $50 \mathrm{keV} \mathrm{Si}$ implant experimental data. Martin Giles also provided us with invaluable advice and encouragement during the development of the kMC simulator, as did Majeed Foad of Applied Materials Corporation. Interactions with Mark Law, Kevin Jones, and Aaron Lilak at the University of Florida throughout the lifetime of the project were most valuable and served to keep us grounded in 
reality. Many fruitful discussions and interactions with George Gilmer, Lourdes Pelaz, David Eaglesham, Martin Jaraiz, and Hans Gossmann of Lucent Technologies Bell Laboratories are gratefully acknowledged.

\section{REFERENCES}

"Present address: Avant! TCAD Engineering, 46871 Bayside Pkwy, Fremont, CA 94538.

${ }^{\dagger}$ Present address: Visto Corp., 1937 Landings Drive, Mountain View, CA 94043.

1. Senniconductor Industry Assn., The National Technology Roadmap for Semiconductois, SEMATECH (1997).

2. A.E. Michel, Appl. Phys. Lett. 50, 416 (1987).

3. N.E.B. Cowern, J. Appl. Phys. 64, 4484 (1988).

4. S. Solmi and F. Baruffaldi, J. Appl. Phys. 69, 3384 (1988).

5. K.S. Jones, H.G. Robinson, J. Listebarger, J. Chen, J. Liu, B. Herner, H. Park, M.E. Law, D. Sieloff, and J.A. Slinkman, Nucl. Instrum. Methods Phys. Res. B 96, 196 (1995).

6. 2. P. M. Fahey, P. B. Griffin, J. D. Plummer, Rev. Mod. Phys. 61, 289 (1989).

7. S. Tian, S. J. Morris, B. Obradovic, M. F. Morris, G. Wang, G. Balamurugan, A. F. Tasch, C. Snell, UT-Marlowe, Version 4.0 (1996).

8. J. R. Beeler, jr. Radiation Effects Computer Experiments, (North Holland, Amsterdam, 1983).

9. D.G. Besco, Computer Simulation of point defect annealing in metals, USA-AEC report GEMP-644, October 1967.

10. D.G. Doran, Rad. Eff. 2, 249 (1970).

11. D.G. Doran and R.A Burnett, in Interatomic Potentials and Simulations of Lattice Defects, ed. P.C. Gehlen, J.R. Beeler, jr. and R.I Jaffee, (Plenum Press, New York, 1972) p.403.

12. H. Heinisch, J. Nucl. Mater. 117, 46 (1983). H. Heinisch, B.N. Singh and T. Diaz de la Rubia, J. Nucl. Mater. 212-215, 127 (1994). H. Heinisch and B.N. Singh, J. Nucl. Mater. 191-194, 125 (1992). H. Heinisch and B.N. Singh, J. Nucl. Mater. 251, 77 (1997).

13. N. Soneda and T. Diaz de la Rubia, Philos. Mag. A 78, 995 (1998).

14. T. Diaz de la Rubia, N. Soneda, M.J. Caturla and E. Alonso, J. Nucl. Mater. 251, 13 (1997).

15. M.D. Johnson, M.-J. Caturla, and T. Diaz de la Rubia, J. Appl. Phys. 84, 1963 (1998).

16. M.-J. Caturla, M.D. Johnson, and T. Diaz de la Rubia, Appl. Phys. Lett. 72, 2736 (1998).

17. M.-J. Caturla, Comp. Mat. Sci. 12, 319 (1998).

18. S.K. Theiss, M.-J. Caturla, T. Diaz de la Rubia, M.D. Johnson, Ant Ural, and P.B. Griffin, Mat. Res. Soc. Symp. Proc. 538, (1999), in press.

19. M. Jaraiz, G. H. Gilmer, J. M. Poate, T. Diaz de la Rubia, Appl. Phys. Lett. 68, 409 (1996).

20. L. Pelaz, M. Jaraiz, G. H. Gilmer, H.-J. Gossmann, Appl. Phys. Lett. 70, 2285 (1997). L. Pelaz, G. H. Gilmer, M. Jaraiz, S. B. Herner, H.-J. Gossmann, D. J. Eaglesham, G. Hobler, C. S. Rafferty, and J. Barbolla, Appl. Phys. Lett. 73, 1421 (1998).

21. C. S. Nichols, C. G. Van de Walle, S. T. Pantelides, Phys. Rev. B40, 5458 (1989). 
22. W.A. Harrison, Mat. Res. Soc. Symp. Proc. 469, 211 (1997).

23. J. Zhu, T. Diaz de la Rubia, L. H. Yang, C. Mailhiot, G. H. Gilmer, Phys. Rev. B54, 4741 (1996).

24. M. Tang, L. Colombo, J. Zhu, T. Diaz de la Rubia, Phys. Rev. B55, (1997).

25. G. H. Gilmer, T. Diaz de la Rubia, D. M. Stock and M. Jaraiz, Nucl. Instrum. and Methods B102, 247 (1995).

26. S. Coffa and S. Libertino, Appl. Phys. Lett. 73, 3369 (1998).

27. A. Bongiorno, L. Colombo, and T. Diaz de la Rubia, Europhys. Lett. 43, 695 (1998).

28. L. Colombo, A. Bongiorno, F. Cargnoni, C. Gatti, and M. Rosati, Mat. Res. Soc. Symp. Proc. 538 (1999), in press.

29. A. Bongiorno, L. Colombo, F. Cargnoni, C. Gatti, and M. Rosati, submitted for publication (January 1999).

30. P.A. Stolk, H.-J. Gossmann, D.J. Eaglesham, D.C. Jacobson, C.S. Rafferty, G.H. Gilmer, M. Jaraiz, J.M. Poate, H.S. Luftman, and T.E. Haynes, J. Appl. Phys. 81, 6031 (1997).

31. J. Zhu, Mat. Res. Soc. Symp. Proc. 469, 151 (1997).

32. O. Pankratov, H. Huang, T. Diaz de la Rubia, C. Mailhiot, Phys. Rev. B 56, 13172 (1997).

33. J.S. Nelson, P.A. Schultz, and A.F. Wright, Appl. Phys. Lett. 73, 247 (1998).

34. H.-J. Gossmann, T.E. Haynes, P.A. Stolk, D.C. Jacobson, G.H. Gilmer, J.M Poate, H.S. Luftman, T.K. Mogi, and M.O. Thompson, Appl. Phys. Lett. 71, 3862 (1997).

35. C.S. Nichols, C.G. Van de Walle, and S.T. Pantelides, Phys. Rev. Lett. 62, 1049 (1989).

36. N.E.B. Cowern, G.F.A. van de Walle, D.J. Gravesteijn, and C.J. Vreizema, Phys. Rev. Lett. 67, 212 (1991).

37. A. D. Kurtz, R. Yee, J. Appl. Phys. 31, 303 (1960).

38. G.D. Watkins and K.L. Brower, Phys. Rev. Lett. 36, 1329 (1976).

39. L.W. Song and G.D. Watkins, Phys. Rev. B 42, 5759 (1990).

40. L.W. Song, X.D. Zhan, B.W. Benson, and G.D. Watkins, Phys. Rev. B 42, 5765 (1990).

41. G. Davies, K.T. Kun, and T. Reade, Phys. Rev. B 44, 12146 (1991).

42. F. Rollert, N.A. Stolwijk, and H. Mehrer, Proc. 15th int. Conf. on Defects in Semiconductors, Budapest (1988).

43. M.T. Robinson and I.M. Torrens, Phys. Rev. B 9, 5008 (1974). M. Hou and M.T. Robinson, Nucl. Instr. Methods 132, 641 (1976). S. Oen and M.T. Robinson, Nucl. Instr. Methods 132, 647 (1976). M.T. Robinson, J. Appl. Phys. 54, 2650 (1983). M.T. Robinson, Phys Rev. B 27, 5347 (1983).

44. K. J. van Oostrum, P.C. Zalm, W.B. deBoer, D.J. Gravesteijn, and J.W.F. Maes, Appl. Phys. Lett. 70, 2285 (1997).

45. H. Bracht, N.A. Stolwijk, and H. Mehrer, Proc. Elcctrochem. Soc. 94-10, 593 (1994).

46. H.-J. Gossmann, C.S. Rafferty, H.S. Luftman, F.C. Unterwald, T. Boone, and J.M Poate, Appl. Phys. Lett. 63, 639 (1993).

47. F.F. Morehead, Mat. Res. Soc. Symp. Proc. 104, 99 (1988).

48. H. Zimmermann and H. Ryssel, Appl. Phys. A 55, 121 (1992).

49. W. Wijaranakula, J. Appl. Phys. 67, 7624 (1990).

50. G.B. Bronner, and J.D. Plummer, J. Appl. Phys. 61, 5286 (1987).

51. T.Y. Tan and U. Gosele, Appl. Phys. A 37, 1 (1985).

52. C. Boit, F. Lau, and R. Sittig, Appl. Phys. A 50, 197 (1990).

53. K. Tanihuchi, D.A. Antonaiadis, and Y. Matsushita, Appl. Phys. Lett. 42, 961 (1983). 
54. K. Ghaderi, G. Hobler, M. Budil, L. Mader, and H.J. Schulze, J. Appl Phys. 77, 1320 (1995).

55. H.-J. Gossmann, G.H. Gilmer, C.S. Rafferty, F.C. Unterwald, T. Boone, J.M. Poate, H.S. Luftman, and W. Frank, J. Appl. Phys. 77, 1948 (1995).

56. A.M. Agarwal and S.T. Dunham, Appl. Phys. Lett. 63, 800 (1993).

57. P.B. Griffin, P.M. Fahey, J.D. Plummer, and R.W. Dutton, Appl. Phys. Lett. 47, 319 (1985).

58. R.K. Jain and R.V. Overstraeten, J. Appl. Phys. 44, 2437 (1973).

59. N.D. Thai, J. Appl. Phys. 41, 2859 (1970).

60. M.D. Giles, IEEE Trans. Comput.-Aided Des. 8, 466 (1989).

61. S. Solmi and F. Baruffaldi, J. Appl. Phys. 69, 2135 (1991).

62. P. A. Packan, J.D. Plummer, Appl. Phys. Lett. 56, 1787 (1990).

63. H. S. Chao, P. B. Griffin, J. D. Plummer, C. S. Rafferty, Appl. Phys. Lett. 69, $2113(1996)$

64. S.B. Felch, Greater Silicon Valley Implant Users Grp. Ann. Symp. Proc., Sunnyvale, CA (1999).

65. M.A. Foad, Greater Silicon Valley Implant Users Grp. Ann. Symp. Proc., Sunnyvale, CA (1999). 


\section{FIGURE CAPTIONS}

Fig. 1 Schematic diagram of the operation of our kinctic Monte Carlo simulator, BIGMAC. The determination of rates and time steps is discussed fully in the text.

Table 1 Origin of values for mobile species required as input to our $\mathrm{kMC}$ simulations.

Fig. $2 \mathrm{~B}$ clustering reactions considered in the simulations presented in this review, with energies in $\mathrm{eV}$ from $a b$ initio calculations. Adding an I ( $\mathrm{Si}$ interstitial) transforms a cluster to the one below it to the left; adding a Bi (mobile $\mathrm{B}$ interstitial) transforms it to the one below and to the right, and adding a vacancy transforms it to the cluster above and to the right. These clustering or annihilation reactions all occur spontaneously. Additionally, $\mathrm{B} 2 \mathrm{I}^{++}$and $\mathrm{B} 3 \mathrm{I}^{+}$each spontaneously emit an $\mathrm{I}^{++}$, to form $\mathrm{B} 2 \mathrm{I}^{\circ}$ and $\mathrm{B} 3 \mathrm{I}^{-}$respectively. The energies given are those used for dissolution in our simulations, and include both the cluster binding energy and the migration energy for the emitted species.

Fig. 3 Steady state effective diffusivity of $\mathrm{Si}$ interstitials in the presence of carbon concentrations from 0 to $1 \times 10^{18} \mathrm{~cm}^{-3}$. The top line is the interstitial diffusivity for a sample with no carbon, and the other lines are fits to the simulation data as follows: $10^{15} \mathrm{C} / \mathrm{cm}^{3}, 0.22 \cdot \exp (-1.26 \mathrm{eV} / \mathrm{kT}) \mathrm{cm}^{2} / \mathrm{s} . \quad 10^{16} \mathrm{C}^{3} \mathrm{~cm}^{3}, 18.5 \cdot \exp (-1.7 \mathrm{eV} / \mathrm{kT}) \mathrm{cm}^{2} / \mathrm{s}$. $10^{17} \mathrm{C} / \mathrm{cm}^{3}, 11.2 \cdot \exp (-1.83 \mathrm{eV} / \mathrm{kT}) \mathrm{cm}^{2} / \mathrm{s} .10^{18} \mathrm{C} / \mathrm{cm}^{3}, 5.8 \cdot \exp (-1.98 \mathrm{eV} / \mathrm{kT}) \mathrm{cm}^{2} / \mathrm{s}$.

Fig. 4 Comparison between the experimentally measured (dashed lines, open symbols) and the simulated (solid lines, closed symbols) Si self-interstitial diffusivities. Results labeled 1-13 correspond to references $45-57$, respectively.

Fig. 5 Experiment and simulation of B diffusion during OED of two different structures with six B spikes. Initial peak B concentrations were (a) $1 \times 10^{18} \mathrm{~cm}^{-3}$, and (b) $1 \times 10^{19} \mathrm{~cm}^{-3}$. The as-deposited profiles (dotted lines) were used as the starting point for $\mathrm{kMC}$ simulations. The experimental profiles after $15 \mathrm{~min}$. annealing at $810^{\circ} \mathrm{C}$ are shown by the solid lines. The simulated results (diamonds) are obtained with a surface $\mathrm{Si}$ interstitial concentration of $2 \times 10^{10} \mathrm{~cm}^{-3}$ and a uniform $\mathrm{C}$ concentration of $5 \times 10^{17} \mathrm{~cm}^{-3}$. Significant B-I clustering (dashed line) was observed only in the high B concentration case. Fermi level effects, which are not included in these simulations, are the probable cause of the discrepancy in (b) between the experiments and the simulations.

Fig. 6 (a) Simulated B diffusivity as a function of depth for two different B concentrations. Assuming the B diffusivity is proportional to interstitial concentrations, a fit to a complementary error function (lines) yields an effective interstitial diffusivity of $2.2 \times 10^{-12} \mathrm{~cm}^{2} / \mathrm{s}$ for the low B concentration spikes (triangles), and $8.6 \times 10^{-13} \mathrm{~cm}^{2} / \mathrm{s}$ for the high $\mathrm{B}$ concentration spikes (squares). (b) Si interstitial profile following OED in low concentration (dashed) and high concentration (solid) B spike structures. The fits to the interstitial profiles yield $3.6 \times 10^{-12}$ and $3.3 \times 10^{-12} \mathrm{~cm}^{2} / \mathrm{s}$ for the low concentration and high 
concentration structures, respectively. These are substantially below the diffusivity for bare $\mathrm{Si}$ interstitials, assumed to be $\sim 6.5 \times 10^{-7} \mathrm{~cm}^{2} / \mathrm{s}$ at $810^{\circ} \mathrm{C}$.

Fig. 7 B profiles following $40 \mathrm{keV} \mathrm{B}$ implantation at $2 \times 10^{14} \mathrm{~cm}^{-2}$ after annealing at (a) $700^{\circ} \mathrm{C}$ for $240 \mathrm{~min}$., (b) $800^{\circ} \mathrm{C}$ for $60 \mathrm{~min}$., and (c) $900^{\circ} \mathrm{C}$ for $5 \mathrm{~min}$. The solid line is experimental data, the circles are the total $\mathrm{B}$ profile from $\mathrm{kMC}$ simulations, and the $\times \mathrm{s}$ are the $\mathrm{kMC}$ results for the $\mathrm{B}$ concentration in B-I clusters.

Fig 8 Time evolution of the substitutional and clustered $\mathrm{B}$ fractions during an $800^{\circ} \mathrm{C}$ anneal of the $40 \mathrm{keV}$ B profile shown in Fig. 7. The percentage of electrically active $\mathrm{B}$ is shown on the right axis, while the concentration of B-I complexes are on the left axis. The fraction of B that is in substitutional sites increases from $56 \%$ after the implant to $98 \%$ after $10^{-2} \mathrm{~s}$ annealing time. However, it starts to decrease again after $10 \mathrm{~s}$, as the vacancies disappear and the Si interstitial and B3I clusters start to grow.

Fig. $9 \Lambda$ verage vacancy and interstitial cluster size (left axis) and total $B$ diffusion length (right axis) vs. time at $800^{\circ} \mathrm{C}$.

Fig. $10 \mathrm{~B}$ diffusivity (circles, left axis) and total diffusion length (squares, right axis) after the transient as a function of temperature from $\mathrm{kMC}$ simulations. Note that the total diffusion length at the end of the transient decreases with increasing temperature.

Fig. 11 B profiles following $60 \mathrm{~min}$. anneals at $800^{\circ} \mathrm{C}$ for $2 \times 10^{14} \mathrm{~cm}^{-2}$ implants at (a) 20 $\mathrm{keV}$ and (b) $80 \mathrm{keV}$. The solid line is experimental data, the circles are the total B profile from $\mathrm{kMC}$ simulations, and the $\times \mathrm{s}$ are the $\mathrm{kMC}$ results for the $\mathrm{B}$ concentration in B-I clusters.

Fig. $12 \mathrm{~B}$ diffusivity at $800^{\circ} \mathrm{C}$ as a function of implant energy (circles, left axis). Also shown is the areal density of $\mathrm{Si}$ interstitials that have recombined with the surface (squares, right axis). As the energy decreases, the number of available interstitials decreases due to faster recombination with the surface. Therefore, TED decreases slightly with decreasing energy.

Fig. 13 Comparison of simulations and experimental results for $50 \mathrm{keV} \mathrm{Si} \mathrm{implants} \mathrm{into}$ CVD-grown B spike structures. As grown total B profiles shown by dashed line. Experimental results for total B concentration after RTAs shown by solid lines. Simulation results for total B shown by filled circles, for B3I clusters shown by xs. (a) $750^{\circ} \mathrm{C}$ anneal, $15 \mathrm{~s}$. (b) $750^{\circ} \mathrm{C}$ anneal, $255 \mathrm{~s}$. (c) $850^{\circ} \mathrm{C}$ anneal, $195 \mathrm{~s}$. (d) $1050^{\circ} \mathrm{C}$ anneal, $105 \mathrm{~s}$. 
Fig. 1

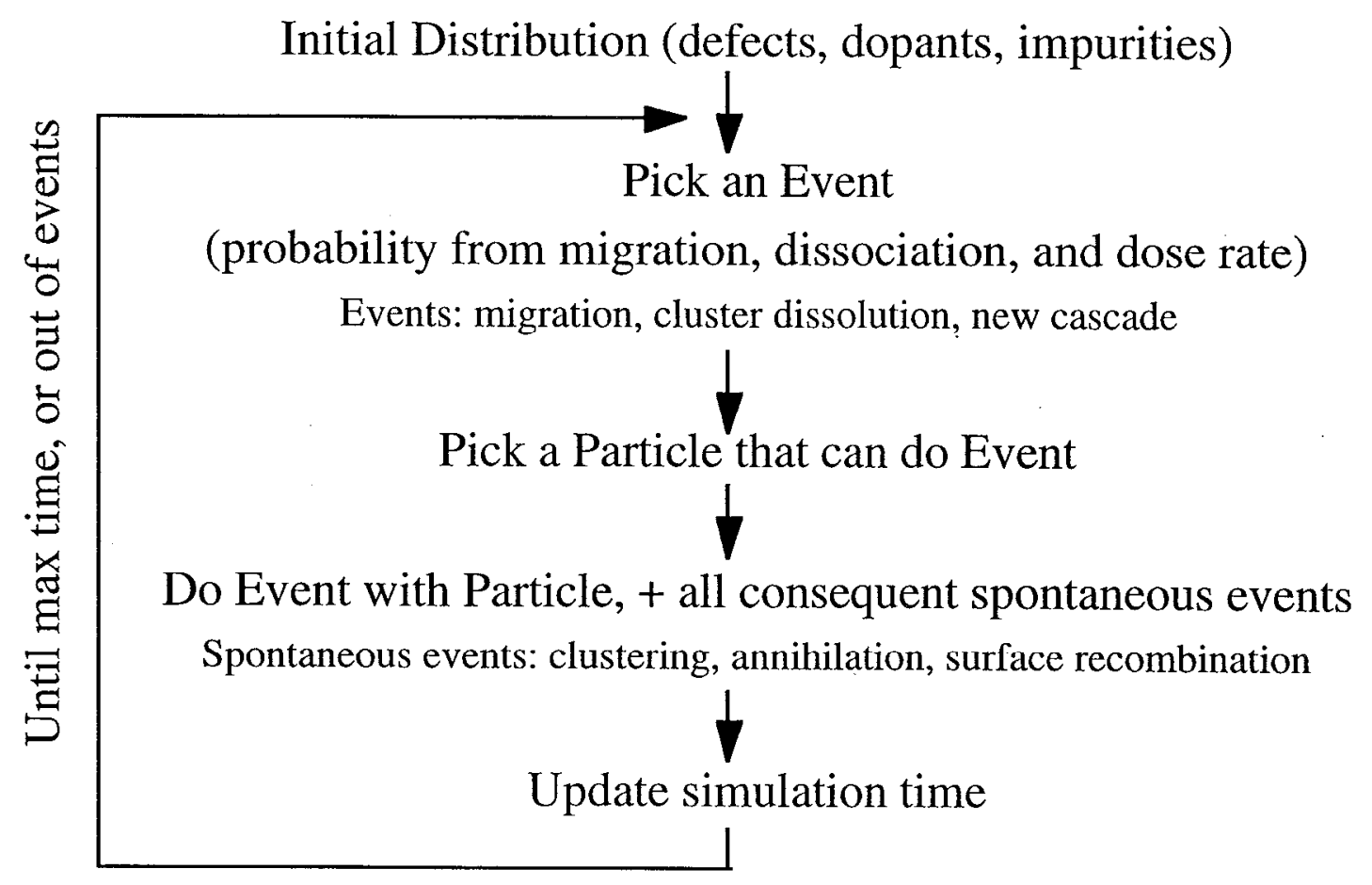


Table 1

\begin{tabular}{ccccc} 
& \multicolumn{2}{c}{ Migration Energy } & \multicolumn{2}{c}{ Prefactor } \\
\cline { 2 - 4 } Species & Value $(\mathrm{eV})$ & Source & Value $\left(\mathrm{cm}^{2} / \mathrm{s}\right)$ & Source \\
\hline $\mathrm{I}$ & 0.9 & MD/ab initio & 2 & Fit to exp. ${ }^{22}$ \\
$\mathrm{~V}$ & 0.43 & $\mathrm{MD}$ & $5 \times 10^{-6}$ & ${\text { Fit to exp. }{ }^{22}}^{29}$ \\
$\mathrm{Bi}$ & 0.3 & ab initio & $2 \times 10^{-5}$ & Fit to exp. ${ }^{34}$ \\
$\mathrm{CI}$ & 0.8 & Exp./ab initio & $5 \times 10^{-5}$ & Fit to exp.
\end{tabular}


Fig. 2

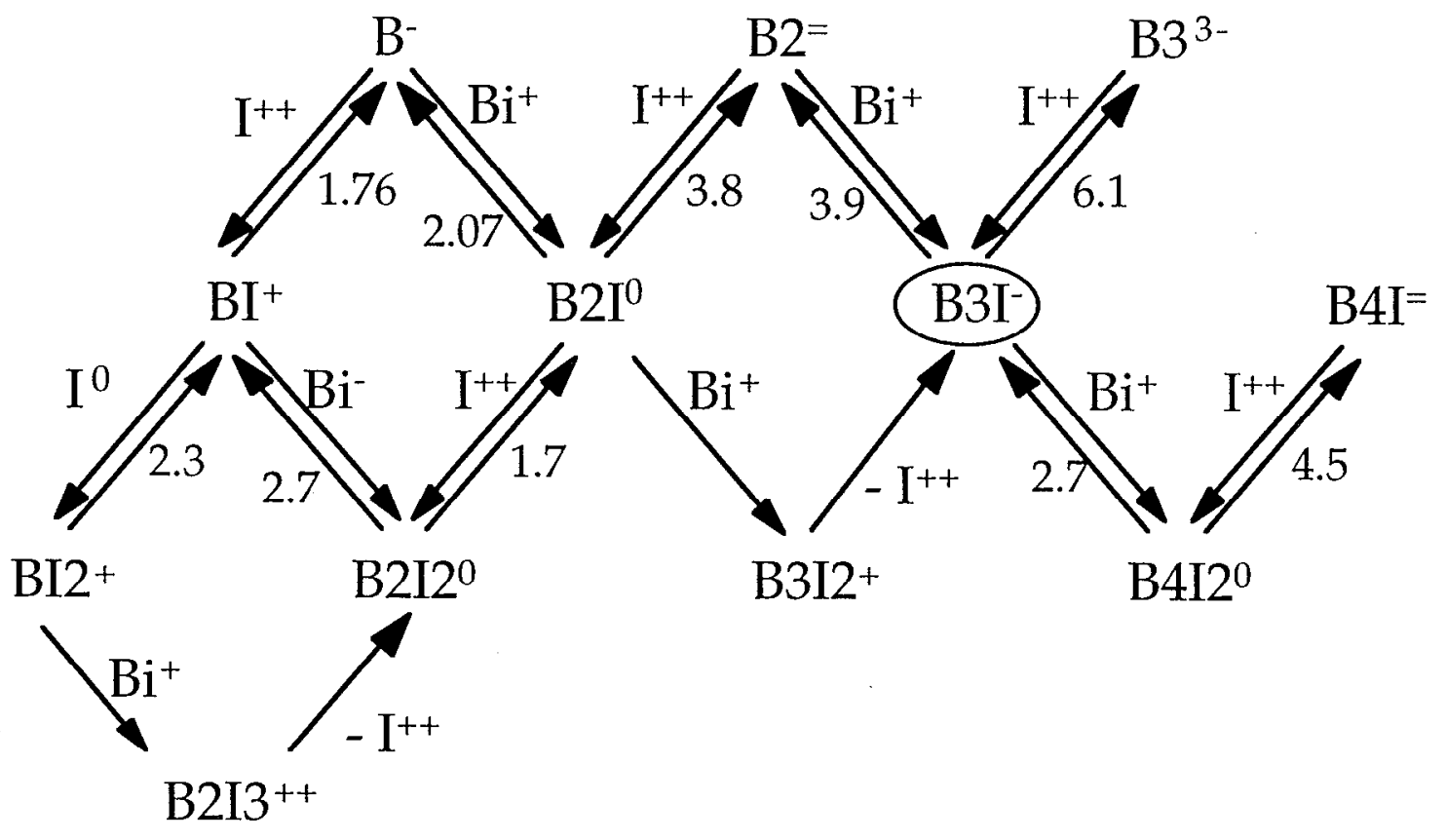


Fig. 3

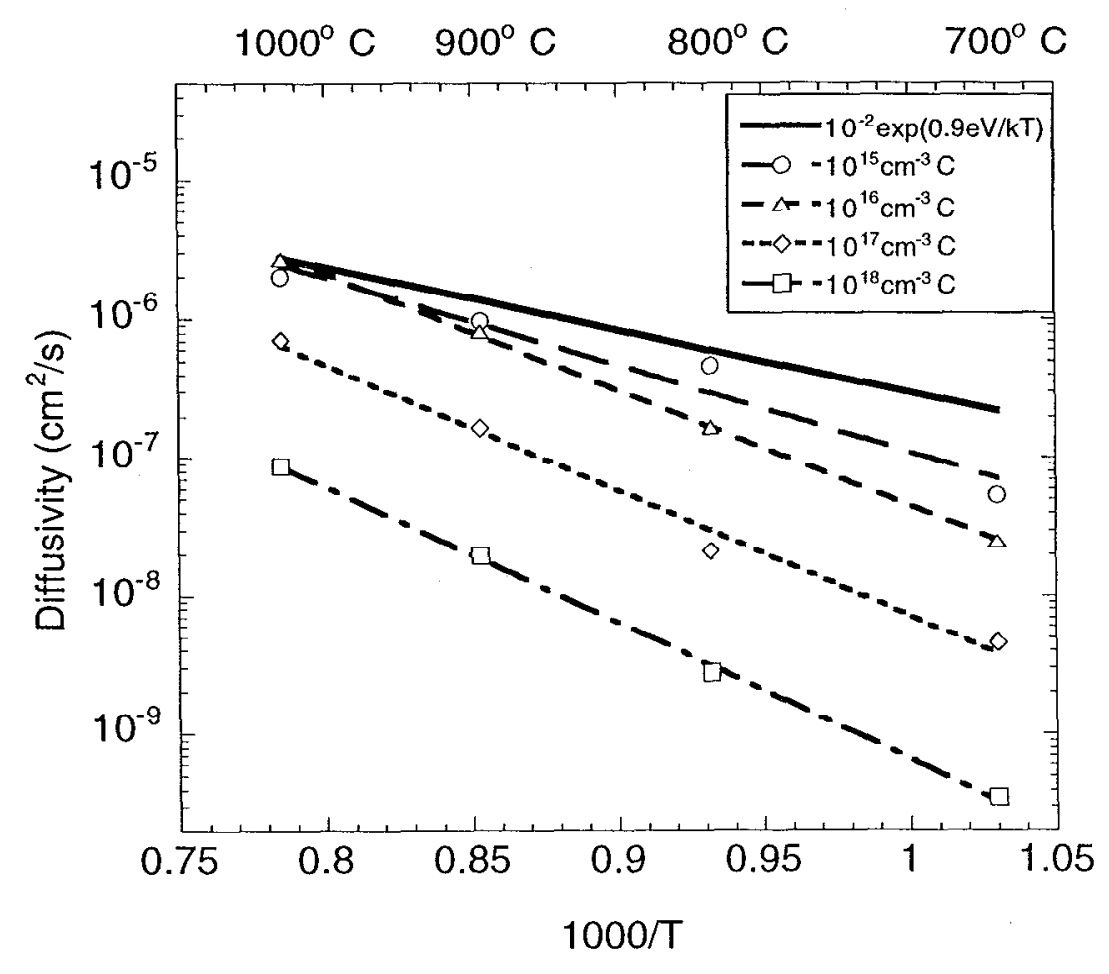


Fig. 4

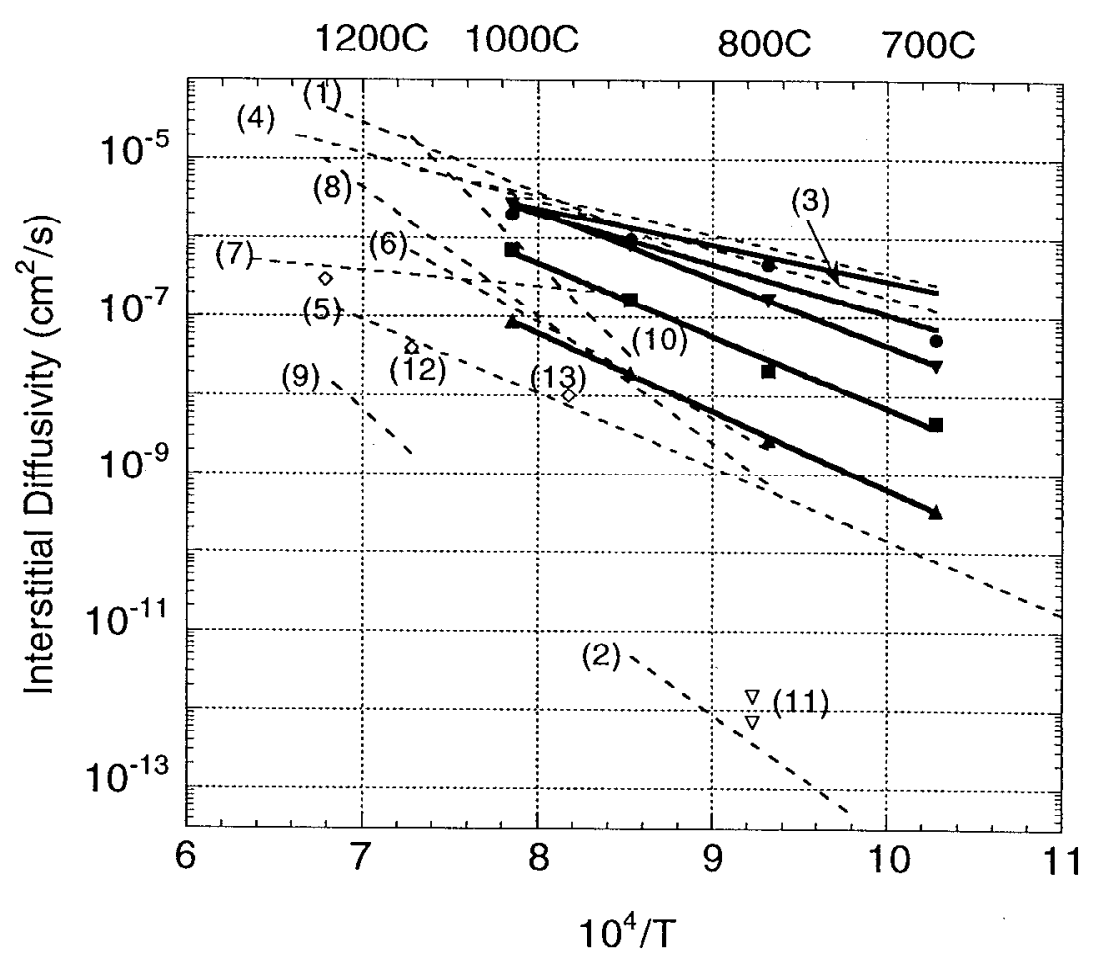


Fig. 5

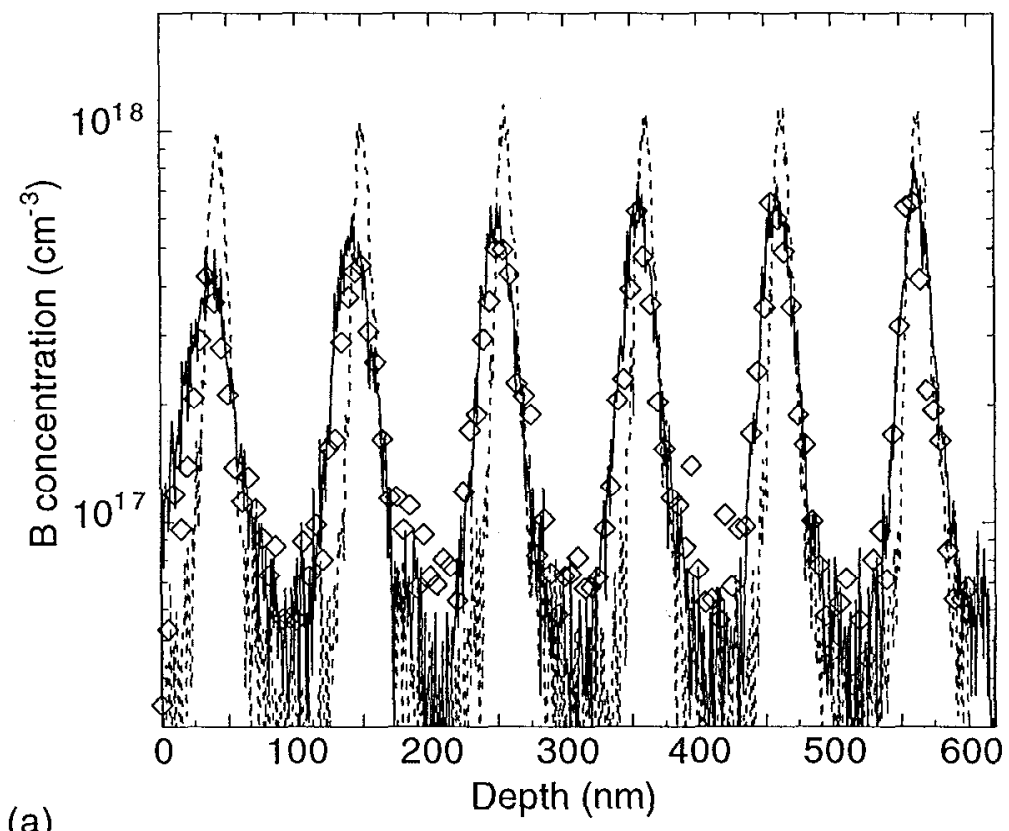

(a)

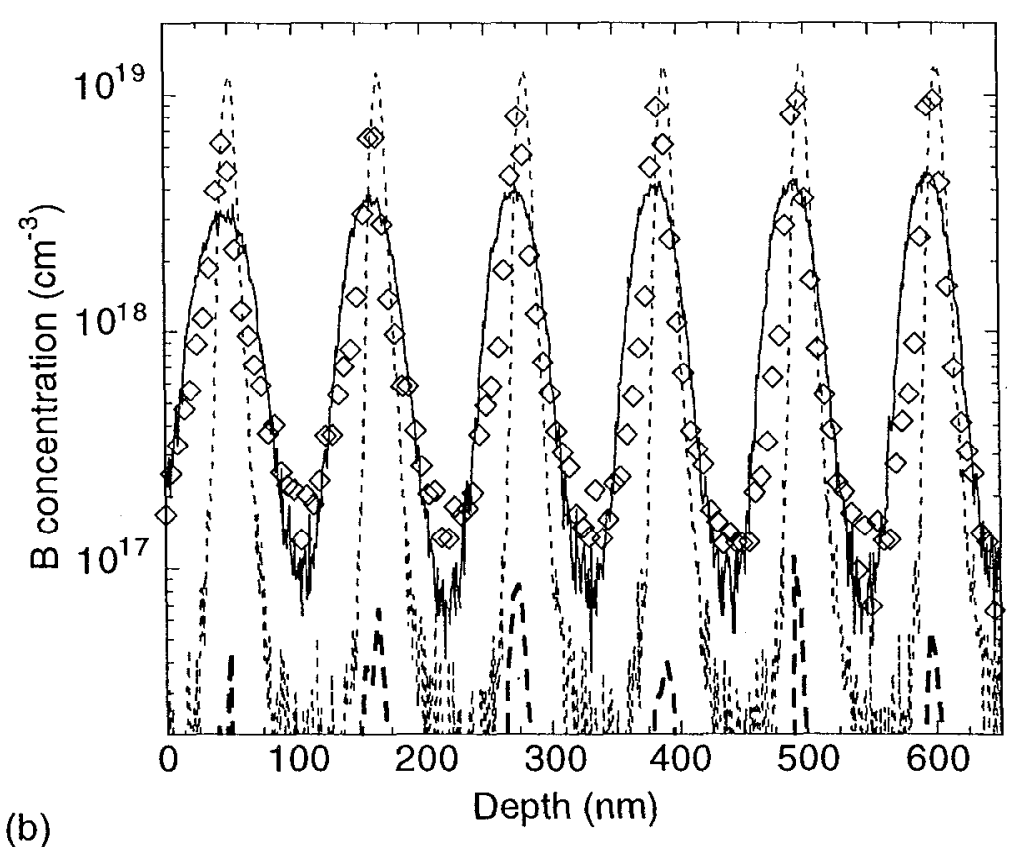


Fig. 6
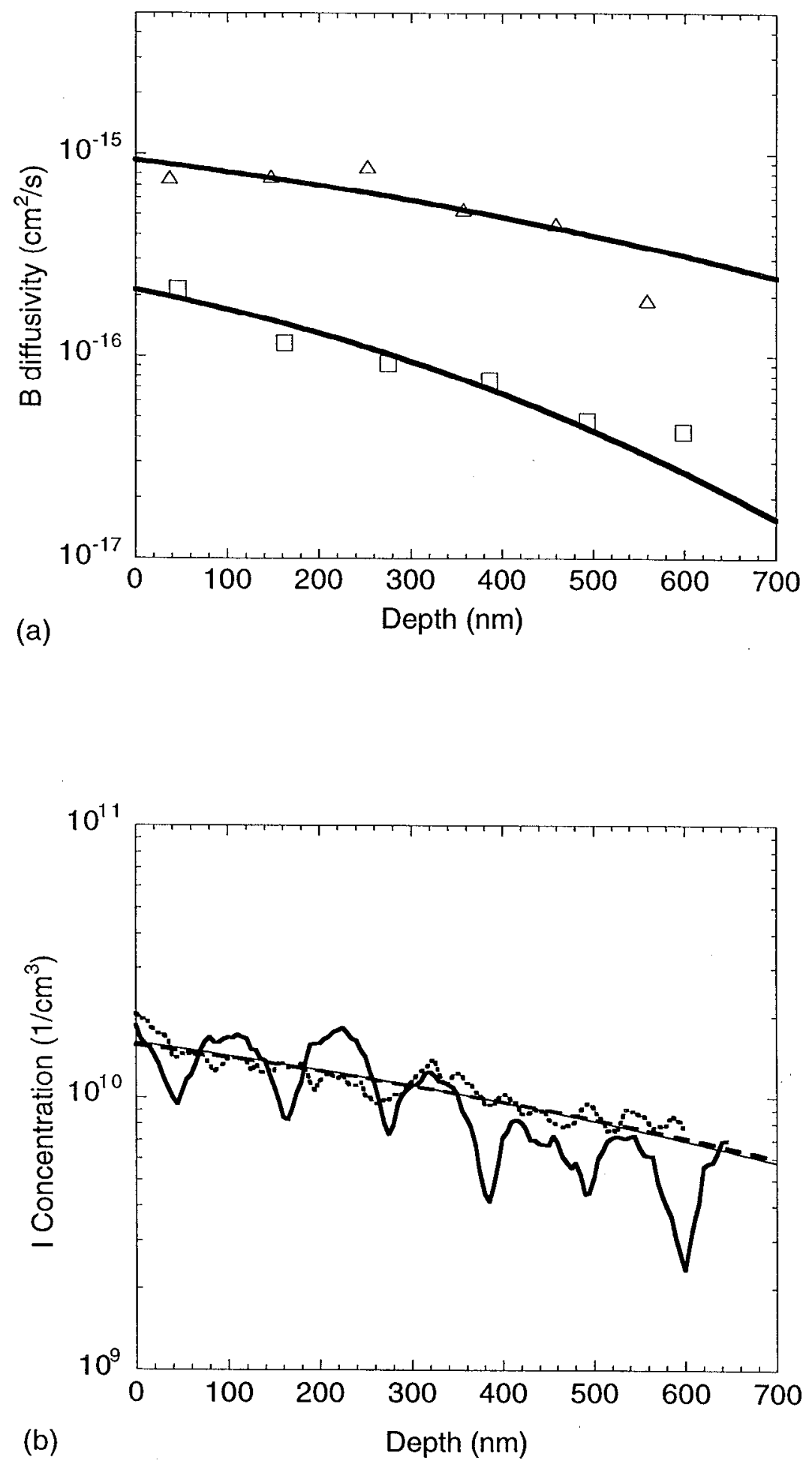
Fig. 7
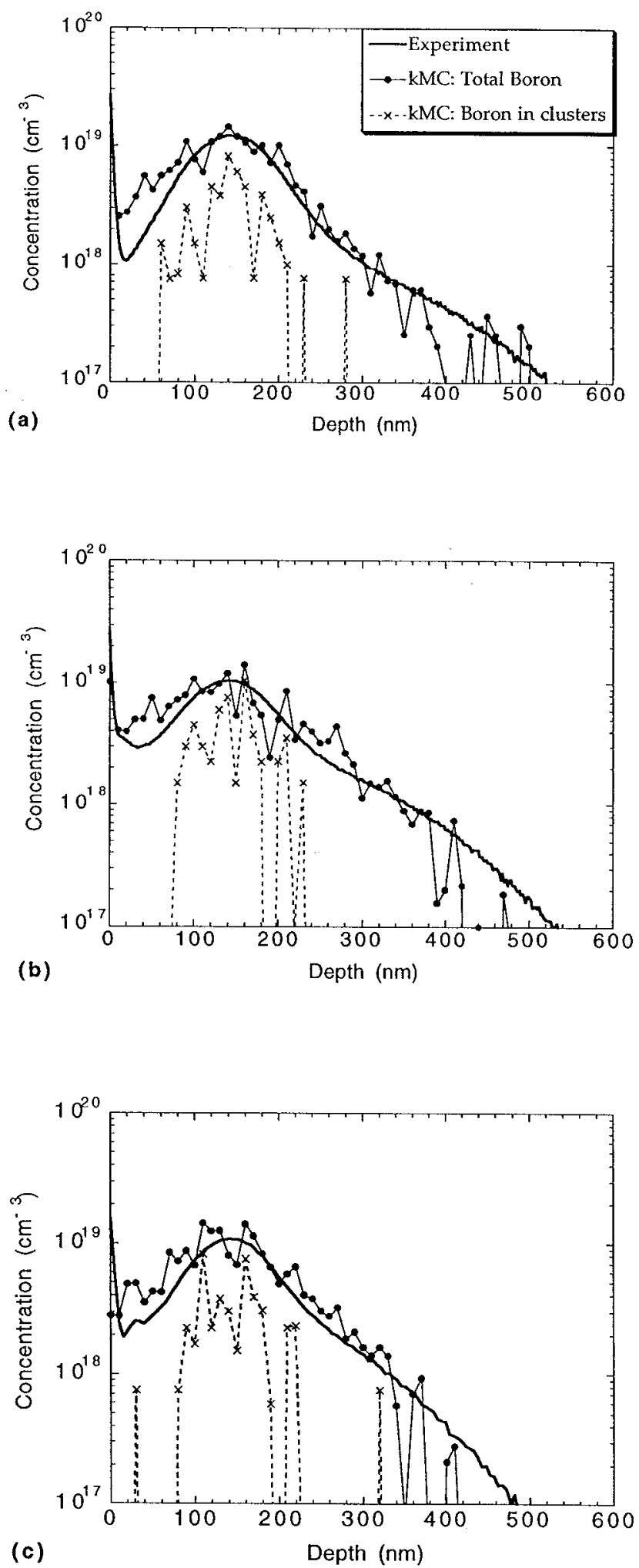
Fig. 8

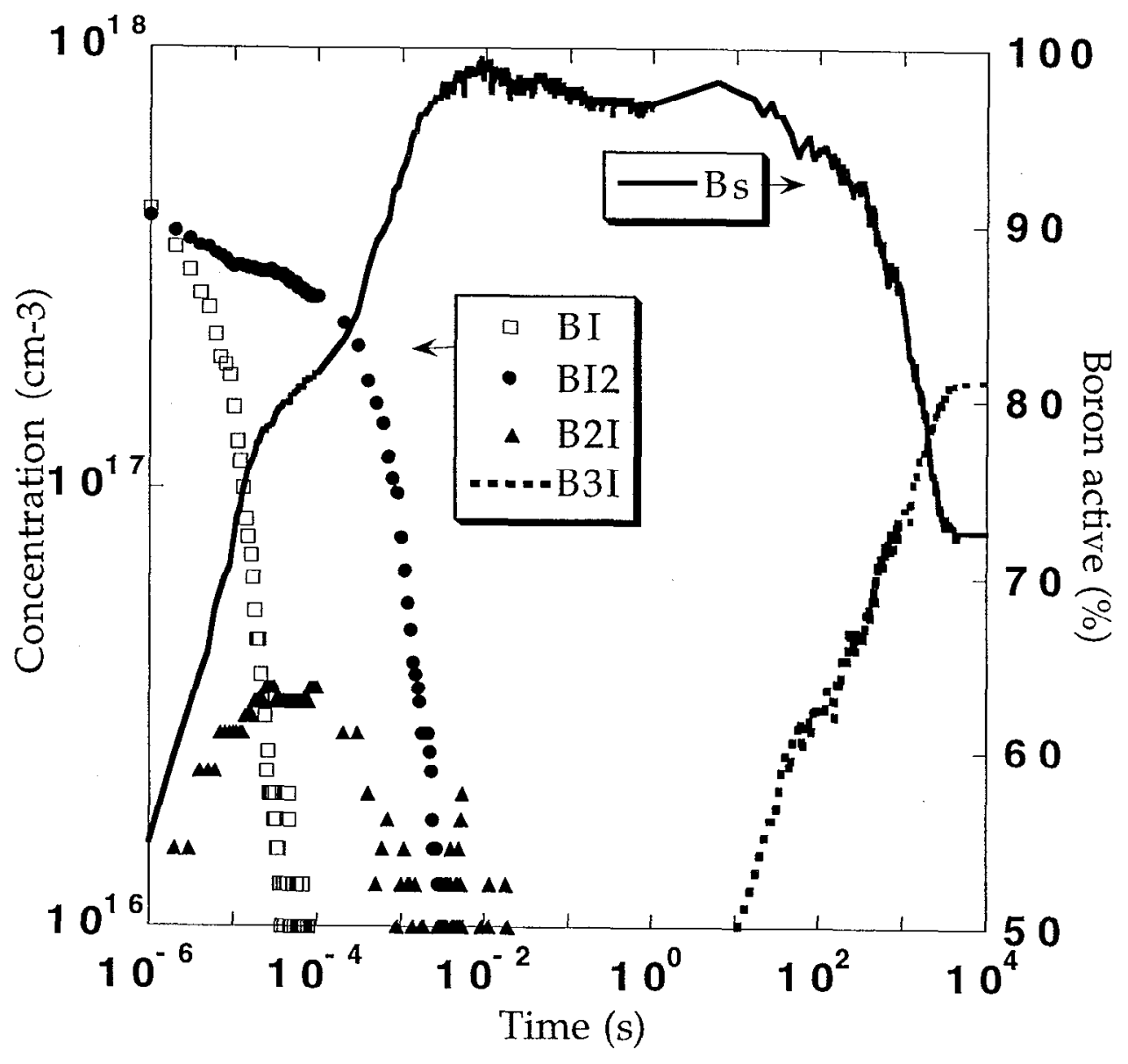


Fig. 9

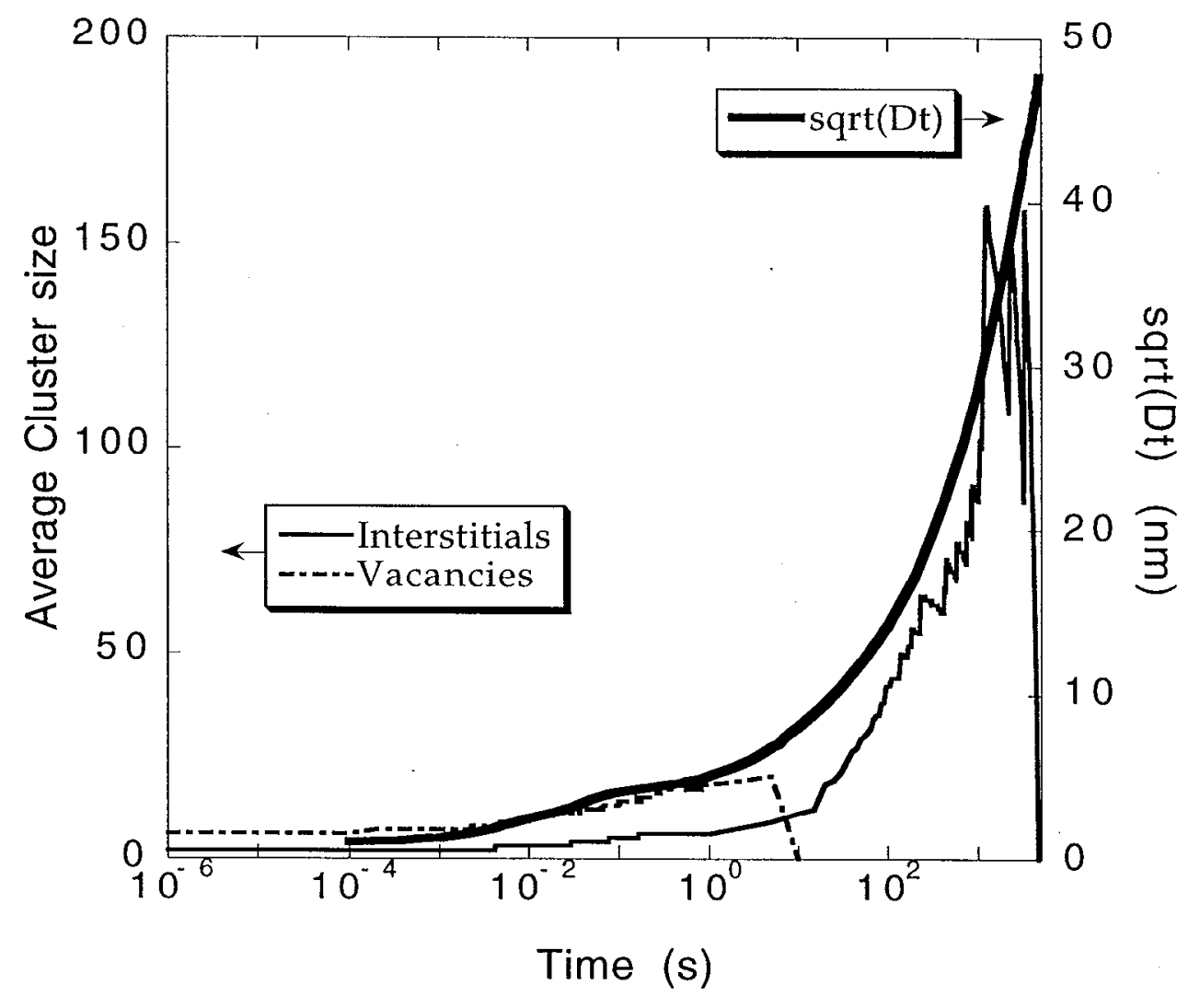


Fig. 10

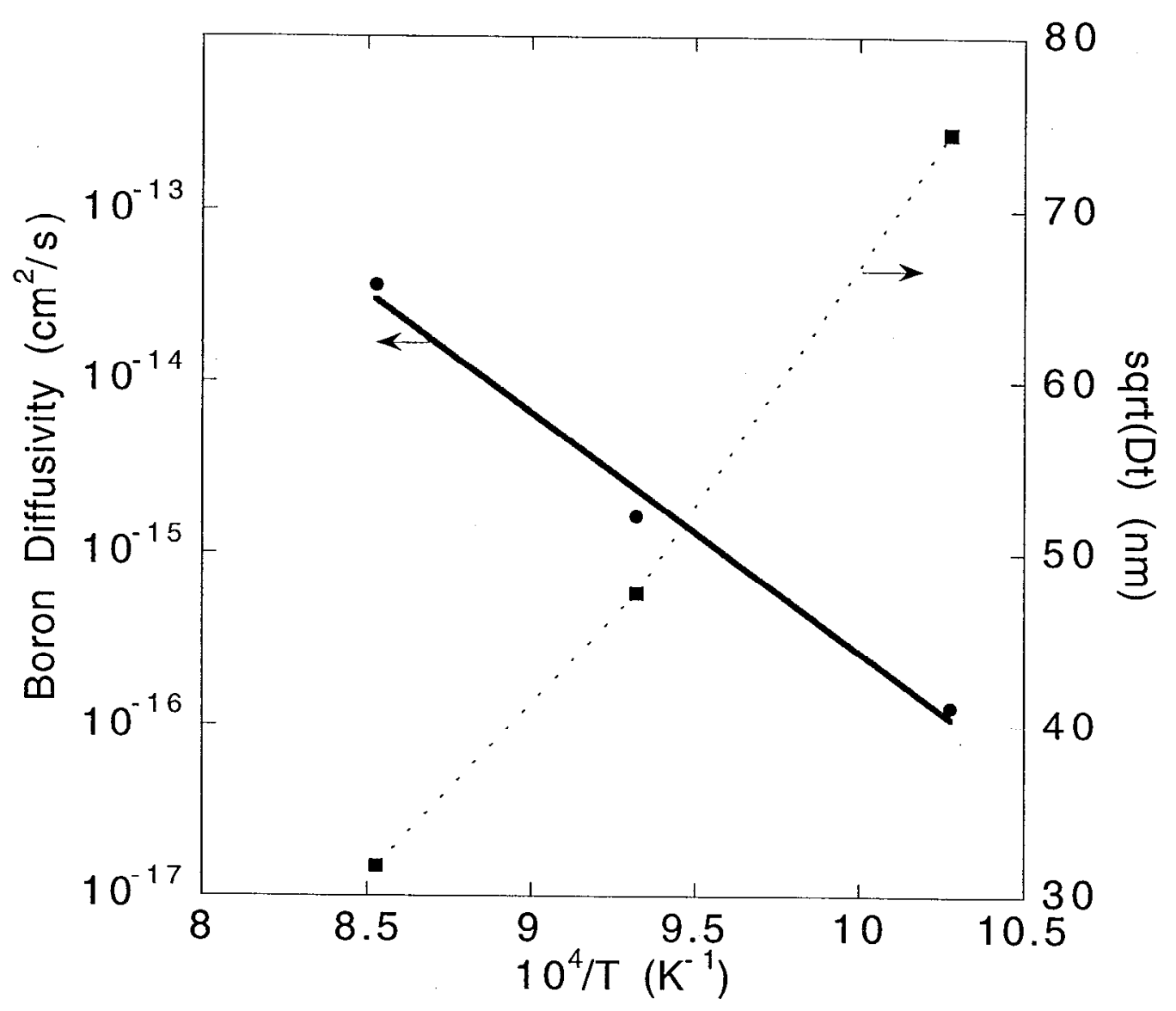


Fig. 11
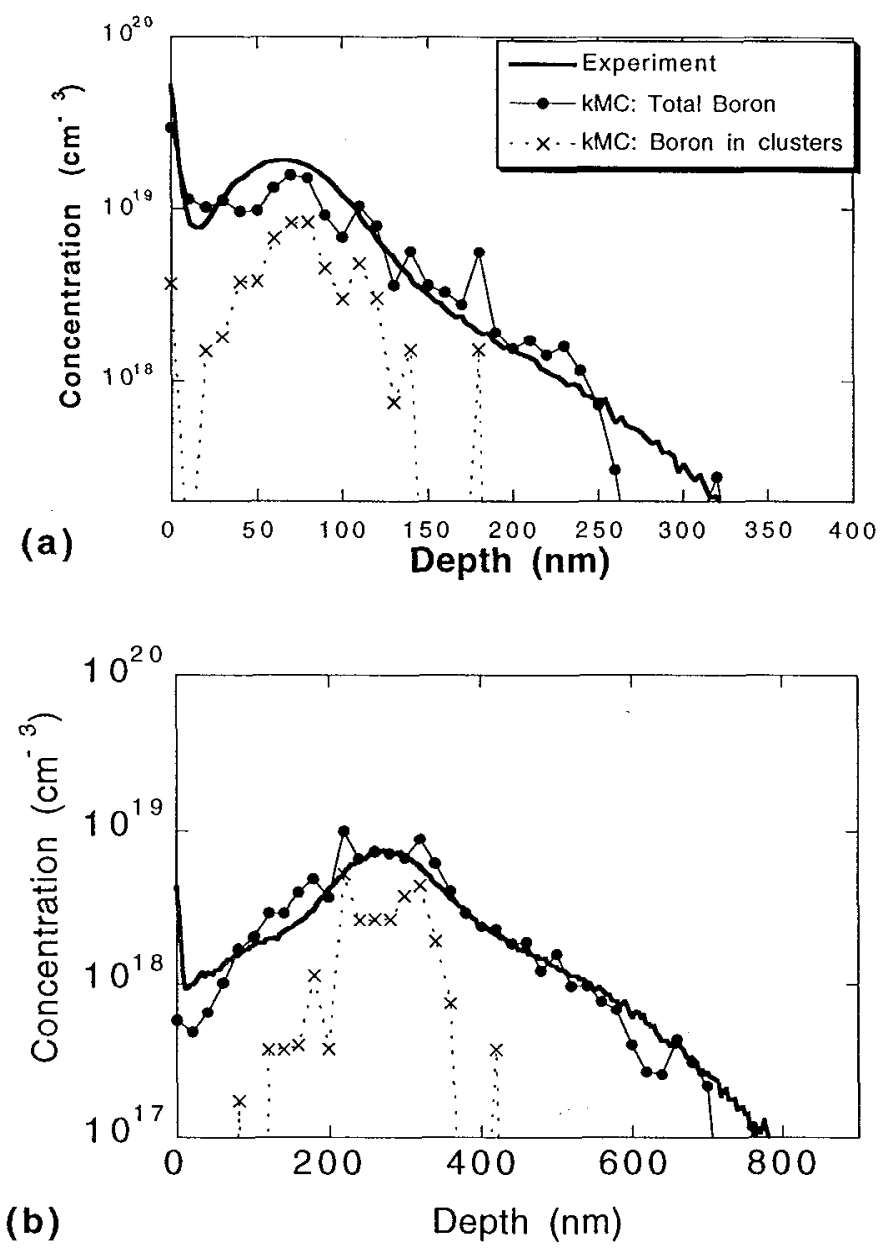
Fig. 12

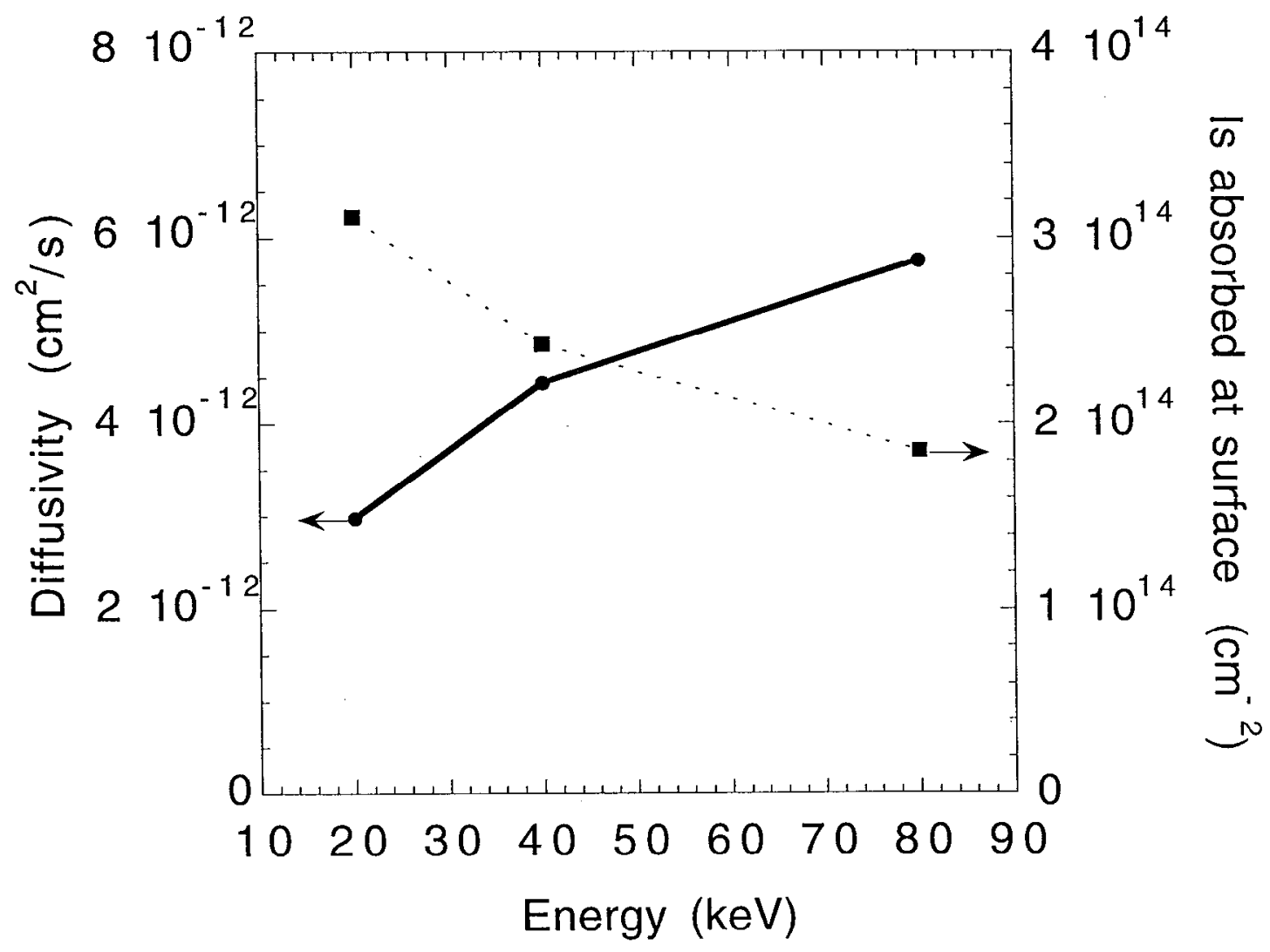


Figure 13
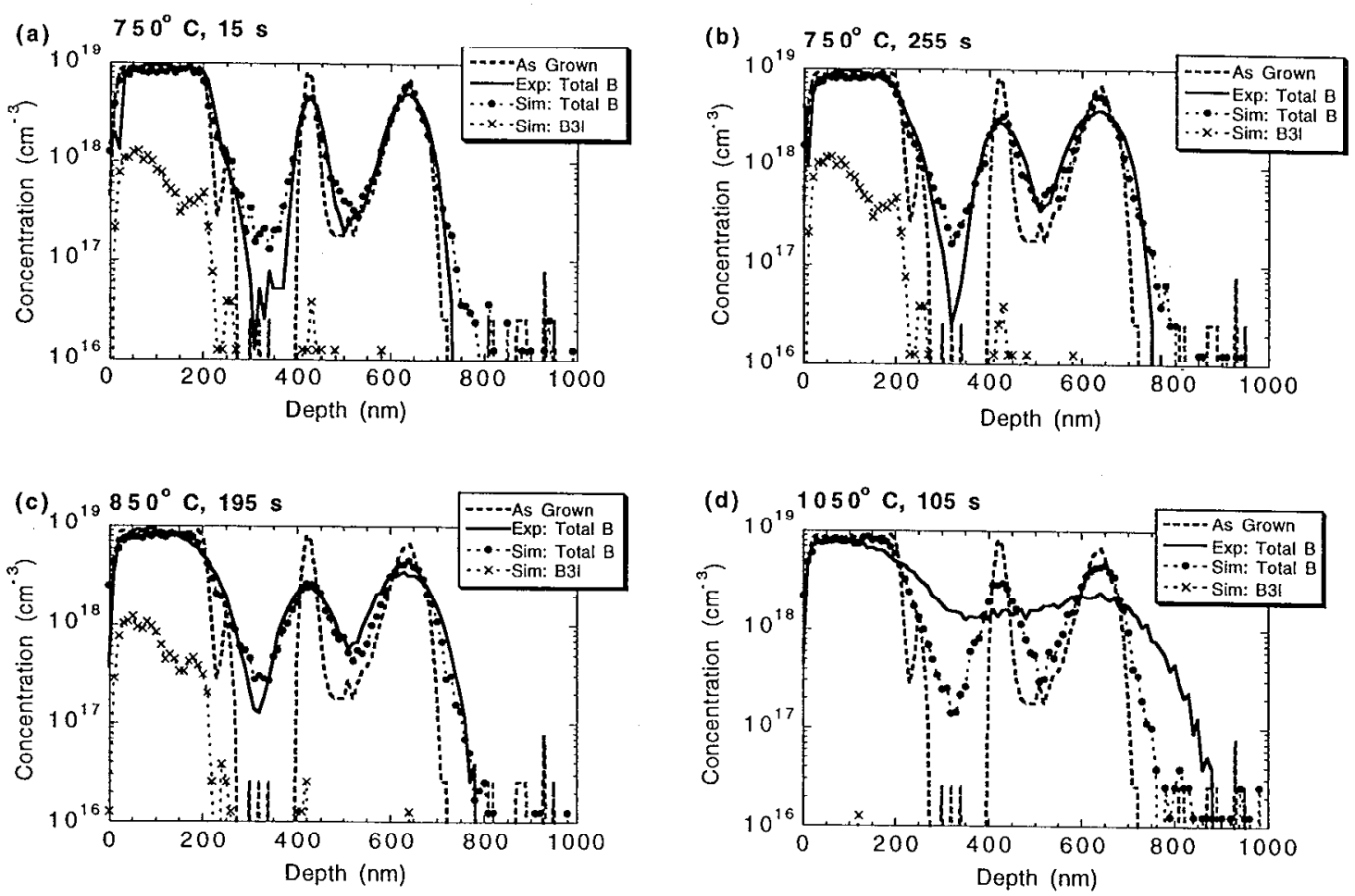